\title{
Interactions of Wnt $/ \beta$-Catenin Signaling and Sonic Hedgehog Regulate the Neurogenesis of Ventral Midbrain Dopamine Neurons
}

\author{
Mianzhi Tang, ${ }^{1}$ J. Carlos Villaescusa, ${ }^{2}$ Sarah X. Luo, ${ }^{3}$ Camilla Guitarte, ${ }^{1}$ Simonia Lei, ${ }^{1}$ Yasunori Miyamoto, ${ }^{4}$ \\ Makoto M. Taketo, ${ }^{5}$ Ernest Arenas, ${ }^{2}$ and Eric J. Huang ${ }^{1,3}$ \\ ${ }^{1}$ Department of Pathology, University of California, San Francisco and Pathology Service, Veterans Affairs Medical Center, San Francisco, California 94121, \\ ${ }^{2}$ Laboratory of Molecular Neurobiology, Department of Medical Biochemistry and Biophysics, Karolinska Institute, Stockholm 17177, Sweden, ${ }^{3}$ Program in \\ Neuroscience, University of California, San Francisco, San Francisco, California 94143, ${ }^{4}$ Graduate School of Humanities and Sciences, Ochanomizu \\ University, Bunkyo-ku, Tokyo 112-8610, Japan, and 5Department of Pharmacology, Graduate School of Medicine, Kyoto University, Yoshida-Konoé-cho, \\ Sakyo, Kyoto 606-8501, Japan
}

Signaling mechanisms involving Wnt/ $\beta$-catenin and sonic hedgehog (Shh) are known to regulate the development of ventral midbrain (vMB) dopamine neurons. However, the interactions between these two mechanisms and how such interactions can be targeted to promote a maximal production of dopamine neurons are not fully understood. Here we show that conditional mouse mutants with region-specific activation of $\beta$-catenin signaling in vMB using the Shh-Cre mice show a marked expansion of Sox2-, Ngn2-, and Otx2positive progenitors but perturbs their cell cycle exit and reduces the generation of dopamine neurons. Furthermore, activation of $\beta$-catenin in vMB also results in a progressive loss of Shh expression and Shh target genes. Such antagonistic effects between the activation of Wnt/ $\beta$-catenin and Shh can be recapitulated in vMB progenitors and in mouse embryonic stem cell cultures. Notwithstanding these antagonistic interactions, cell-type-specific activation of $\beta$-catenin in the midline progenitors using the tyrosine hydroxylaseinternal ribosomal entry site-Cre (Th-IRES-Cre) mice leads to increased dopaminergic neurogenesis. Together, these results indicate the presence of a delicate balance between Wnt/ $\beta$-catenin and Shh signaling mechanisms in the progression from progenitors to dopamine neurons. Persistent activation of $\beta$-catenin in early progenitors perturbs their cell cycle progression and antagonizes Shh expression, whereas activation of $\beta$-catenin in midline progenitors promotes the generation of dopamine neurons.

\section{Introduction}

The developing ventral midbrain (vMB) in vertebrates contains a neurogenic niche that is enriched with progenitor cells for dopamine (DA) neurons (Bjorklund and Lindvall, 1984). Within this niche, progenitors for DA neurons undergo lineage specification, migration, and differentiation to become mature DA neurons (Ang, 2006; Prakash and Wurst, 2006; Smidt and Burbach, 2007; Arenas, 2008). Several lines of evidence indicate that two distinct genetic networks critically regulate the development of DA neurons. Sonic hedgehog (Shh) induces the expression of forkhead

\footnotetext{
Received Feb. 15, 2010; revised May 28, 2010; accepted June 3, 2010.

This work was supported by National Institutes of Health Grants NS48393 and RR24858 and Department of Veterans Affairs Merit Review (E.J.H.), as well as grants from the European Commission (Neurostemcell) and the Swedish Research Council (Grant VR2008:2811 and Developmental Biology for Regenerative Medicine)(E.A.). J.C.V. was supported by a Federal of European Biochemical Societies Long-Term Fellowship, and M.T. was supported by the Development Travel Fellowship. We thank Dr. David Anderson for the Ngn2 antibody, Dr. Mike German for the Lmx1a and Nkx6.1 antibodies, Dr. Marten Smidt for the Pitx3 antibody, and members of the Huang Laboratory for helpful discussions.

This article is freely available online through the J Neurosci Open Choice option.

Correspondence should be addressed to either Eric J. Huang or Mianzhi Tang, Pathology Service 113B, Veterans Affairs Medical Center, 4150 Clement Street, San Francisco, CA 94121. E-mail: eric.huang2@ucsf.edu, mianzhi.tang@ucsf.edu.

D0I:10.1523/JNEUROSCI.0860-10.2010

Copyright $\odot 2010$ the authors $\quad 0270-6474 / 10 / 309280-12 \$ 15.00 / 0$
}

transcription factor Foxa2 in vMB through specific Gli (gliomaassociated oncogene homolog) transcription factor binding elements in the enhancer sequence of Foxa2 (Sasaki et al., 1997). Interestingly, the enhancer elements in Shh contain highly conserved binding sites for Foxa2 that regulate the expression of Shh in vMB (Jeong and Epstein, 2003), supporting the notion that Shh and Foxa2 constitute a feedback transcriptional mechanism for mutual expression. Consistent with this notion, mouse mutants with region-specific removal of Foxa 2 in vMB show a severe loss of Shh (Lin et al., 2009). In addition to the Shh-Foxa2 regulatory loop, the canonical Wnt/ $\beta$-catenin signaling mechanism controls a distinct set of transcription factors critical for the development of DA neurons. Specifically, genetic studies in several mouse mutants indicate that Wnt1 and Otx2 (Orthodenticle homeobox 2) form a feedback mechanism to regulate the expression for each gene (Puelles et al., 2004; Vernay et al., 2005; Prakash et al., 2006). Furthermore, in mouse embryonic stem cells (mESCs), Wntl and Lmxla (LIM homeobox transcription factor 1, alpha) form a feedback regulatory mechanism similar to that in Shh-Foxa2 (Chung et al., 2009).

Several Wnts regulate the development of DA neurons in vMB. For instance, Wntl regulates proliferation, specification, neurogenesis in vMB DA progenitors, as well as the survival of 
DA neurons (McMahon and Bradley, 1990; Thomas and Capecchi, 1990; Danielian and McMahon, 1996; Prakash et al., 2006). Other components of the Wnt signaling pathway, including Wnt2, the Wnt receptors Fzd3 and Fzd6, and the Wnt coreceptor Lrp6, have been found to regulate the development of DA neurons (Castelo-Branco et al., 2010; Sousa et al., 2010; Stuebner et al., 2010). Similarly, $\beta$-catenin, a critical Wnt signaling component, is expressed in vMB DA progenitors and is required for the maintenance of adherent junctions, the integrity of radial glia processes, and cell cycle progression of DA progenitors (Joksimovic et al., 2009; Tang et al., 2009).

To further investigate the role of canonical Wnt signaling in DA neurogenesis, we generated conditional mouse mutants in which the glycogen synthase kinase $3 \beta$ (GSK3 $\beta$ ) phosphorylation sites in $\beta$-catenin $\left(\beta-C t n^{E x 3}\right)$ was removed from the neurogenic niche in vMB. Our results indicate that the activation of $\beta$-catenin in vMB promoted a marked expansion of DA progenitors but led to a reduced expression of Shh and Foxa2. Moreover, the antagonistic interaction between the Wnt and Shh pathways in the generation of DA neurons was also detected in the cultures of DA progenitors and mESCs. Conversely, cell-type-specific activation of $\beta$-catenin in midline progenitors promoted DA neurogenesis. These results provide strong evidence that $\mathrm{Wnt} / \beta$-catenin and Shh signaling pathways control a delicate balance of target gene expression during DA neurogenesis.

\section{Materials and Methods}

Animals. To generate conditional activation of $\beta$-catenin in mice, $\beta$-catenin ${ }^{\text {Exon } 3}$ mice $\left(\beta-C t n^{E x 3}\right)$ were crossed with Shh-Cre (stock \#005622; The Jackson Laboratory) or tyrosine hydroxylase-internal ribosomal entry site-Cre (Th-IRES-Cre) (Harada et al., 1999; Harfe et al., 2004; Lindeberg et al., 2004; Tang et al., 2009). Animal care was approved by the Institutional of Animal Care and Use Committee and followed National Institutes of Health guidelines.

Histology and immunohistochemistry. The protocols for histology and immunohistochemistry were the same as described previously (Zhang et al., 2007; Tang et al., 2009). Briefly, mouse embryos, from embryonic day 10.5 (E10.5) to E12.5, were fixed with $1 \%$ paraformaldehyde (PFA) in PBS (4\% PFA for Nkx6.1 antibody). Mice at E18.5, postnatal day $0(\mathrm{P} 0)$, and P21 were perfused and fixed with 4\% PFA, cryoprotected in 15-30\% sucrose solution, and sectioned in the coronal plane using a Leica cryostat. Mouse brains were sectioned at $14 \mu \mathrm{m}$ thickness (for stereology counting, brains were cut at $40 \mu \mathrm{m}$ ) and mounted on Superfrost glass slides.

Sections were incubated with primary antibody overnight and secondary antibodies for $1 \mathrm{~h}$, followed by incubation in DAB solution to detect signals. The primary antibodies in this study included the following: anti-bromodeoxyuridine (BrdU) antibody (1:500; MAB3222; Millipore Bioscience Research Reagents), anti-Foxa2 [1:20; 4C7; Developmental Hybridoma Study Bank (DHSB)], anti-Ki67 (1:200; RM9106-S0; Thermo Fisher Scientific), anti-Lmxla (1:1000; gift from Dr. Mike German, University of California, San Francisco, San Francisco, CA), antiNgn2 (Neurogenin 2) (1:10; gift from Dr. David Anderson, California Institute of Technology, Pasadena, CA), anti-Pitx3 (Pituitary homeobox 3) (1:300; gift from Dr. Marten Smidt, University Medical Center Utrecht, Utrecht, The Netherlands), anti-Nkx2.2 (NK2 transcription factor related, locus 2) (1:50; 74.5A5; DHSB), anti-Nkx6.1 (NK6 homeobox 1) (1:1000; gift from Dr. Mike German), anti-Nurr1 (Nuclear receptor related 1 protein) (1:500; sc-990; Santa Cruz Biotechnology), anti-Otx2 (1:200; ab21990; Abcam), anti-phospho-histone H3 (PH3) (1:200; 06570; Millipore Corporation), anti-Shh (1:200; catalog \#2207; Cell Signaling Technology), anti-TuJ1 class III $\beta$-tubulin (1:2000; MMS435P; Covance), anti-tyrosine hydroxylase (1:1000; AB157; Millipore Bioscience Research Reagents), anti-tyrosine hydroxylase (1:500; ab113; Abcam), and anti- $\beta$-catenin (1:200; catalog \#9587; Cell Signaling Technology). For stereology counting, sections were incubated for $1 \mathrm{~h}$ with biotinylated IgG and avidin-biotin complex (Vector Laboratories).
Images were captured using a Nikon Eclipse E800 fluorescent microscope connected to a SPOT RT camera (Diagnostic Instruments) or a BX41 Olympus microscope equipped with Olympus DP70 CCD camera. Images were captured using Spot Advance or Olympus DP Controller software programs or using an LSM 510 confocal microscope (Carl Zeiss 510 Microimaging).

BrdU labeling of dopaminergic progenitors. We performed two injection schemes. In the first scheme, the pregnant mice were injected with BrdU $(50 \mu \mathrm{g} / \mathrm{g})$ (BD Biosciences) at E10.5 and E12.5, respectively, and killed $2 \mathrm{~h}$ later. In the second scheme, the pregnant mice were injected with BrdU at E10.5 and E11.5, respectively, and killed $24 \mathrm{~h}$ later (Zhang et al., 2007; Tang et al., 2009).

In situ hybridization. In situ hybridization were the same as described previously (Zhang and Huang, 2006). Briefly, RNA probes for in situ hybridization were prepared using plasmid cDNA clones for Shh, cyclin $D 1$, and $L m x 1 b$ transcribed with T7 or T3 polymerase using digoxigenin (DIG)-labeling reagents and a DIG RNA labeling kit (Roche). Embryos were fixed overnight at room temperature in $4 \%$ PFA in DEPC-treated PBS, cryoprotected in 15 and 30\% sucrose in DEPC PBS, and embedded in OCT. Sections were processed at $14 \mu \mathrm{m}$. During hybridization, sections were first postfixed with 4\% PFA and then washed with acetylation solution and $1 \%$ Triton X-100. Then sections were prehybridized with hybridization buffer (Amresco) for 2-4 h before applying hybridization buffer containing DIG-labeled riboprobes $(200-400 \mathrm{ng} / \mathrm{ml})$ at $55^{\circ} \mathrm{C}$ overnight. The second day, slides were washed with $4 \times$ SSC, followed by RNase A $(20 \mu \mathrm{g} / \mathrm{ml})$ treatment at $37^{\circ} \mathrm{C}$ for $45 \mathrm{~min}$ and subsequent washes with $2 \times$ SSC, $1 \times$ SSC, and $0.5 \times$ SSC at room temperature. For visualizing the in situ hybridization results, we used DIG Nucleic Acid Detection kit (Roche). Finally, the slides were dried under room temperature and mounted with Crystal Mount (Biomeda).

Stereology. The total number of TH-positive $\left(\mathrm{TH}^{+}\right)$neurons in substantia nigra pars compacta (SNpc) and ventral tegmental area (VTA) was determined using the optical fractionator, an unbiased cell counting method not affected by the volume of reference (i.e., SNpc or VTA) or the size of the counted elements (i.e., neurons) (Zhang et al., 2007; Tang et al., 2009). Neuronal counts were performed using a computer-assisted image analysis system consisting of an Olympus BX-51 microscope equipped with a $x-y-z$ computer-controlled motorized stage and the StereoInvestigator software (MicroBrightField). $\mathrm{TH}^{+}$neurons were counted in SNpc or VTA of every third section throughout the entire midbrain. Each section was viewed at lower power $(4 \times)$ and outlined. At a random start, the numbers of $\mathrm{TH}$-stained cells were counted at high power $(60 \times$ oil; numerical aperture 1.4$)$ using a $50 \times 50 \mu \mathrm{m}$ counting frame.

Ventral midbrain DA progenitor cultures. Primary cultures for dopamine neurons were prepared from vMB using microisland methods according to published procedures (Takeshima et al., 1996). Briefly, mouse embryos were collected from time-pregnant CD-1 (for E10.5 and E13.5 wild-type cultures) or Shh-Cre (for E12.5 Shh-Cre; $\beta-C t n^{E x 3 /+}$ cultures) females. The ventral midbrain was dissected, dissociated after treatment with trypsin, and cultured on coverslips coated with poly-D-ornithine (Sigma) and laminin (Sigma) at the density of $1.2 \times 10^{6} / \mathrm{ml}$. The dissociated cells were maintained in the DMEM/F-12 (1:1) medium containing $10 \%$ FBS overnight. Then, the differentiated neurons were changed to DMEM/F-12 (1:1) medium containing N2 supplements (Invitrogen), 20 ng/ml FGF2 (Millipore Corporation), 100 ng/ml FGF8 (Peprotech), and designated factors, including Shh (Peprotech), Wnt1 (Peprotech), Wnt5a (R \& D Systems), and the GSK3 $\beta$ inhibitor CT99021 (Axon Medchem) before they were fixed with $4 \%$ PFA. The number of mature DA neurons in culture were determined by counting the total number of $\mathrm{TH}^{+}$neurons per $20 \times$ field (Parish et al., 2008).

Mouse embryonic stem cell cultures. Differentiation of R1 mESCs into DA neurons was performed using a slightly modified protocol (Barberi et al., 2003). Briefly, R1 mESCs were seeded at a density of 50 cells $/ \mathrm{cm}^{2}$ on mitomycin-treated stromal cell PA6 and cultured in ES-Serum Replacement Media, composed by KnockOut-DMEM (Invitrogen), 15\% KnockOut serum replacement (Invitrogen), $0.1 \mathrm{~mm} \beta$-mercaptoethanol (Sigma), $200 \mathrm{~mm}$ L-glutamine (Invitrogen), 1\% nonessential amino acids (Biochrom AG), and $2000 \mathrm{U} / \mathrm{ml}$ penicillin/streptomycin (Invitrogen). 


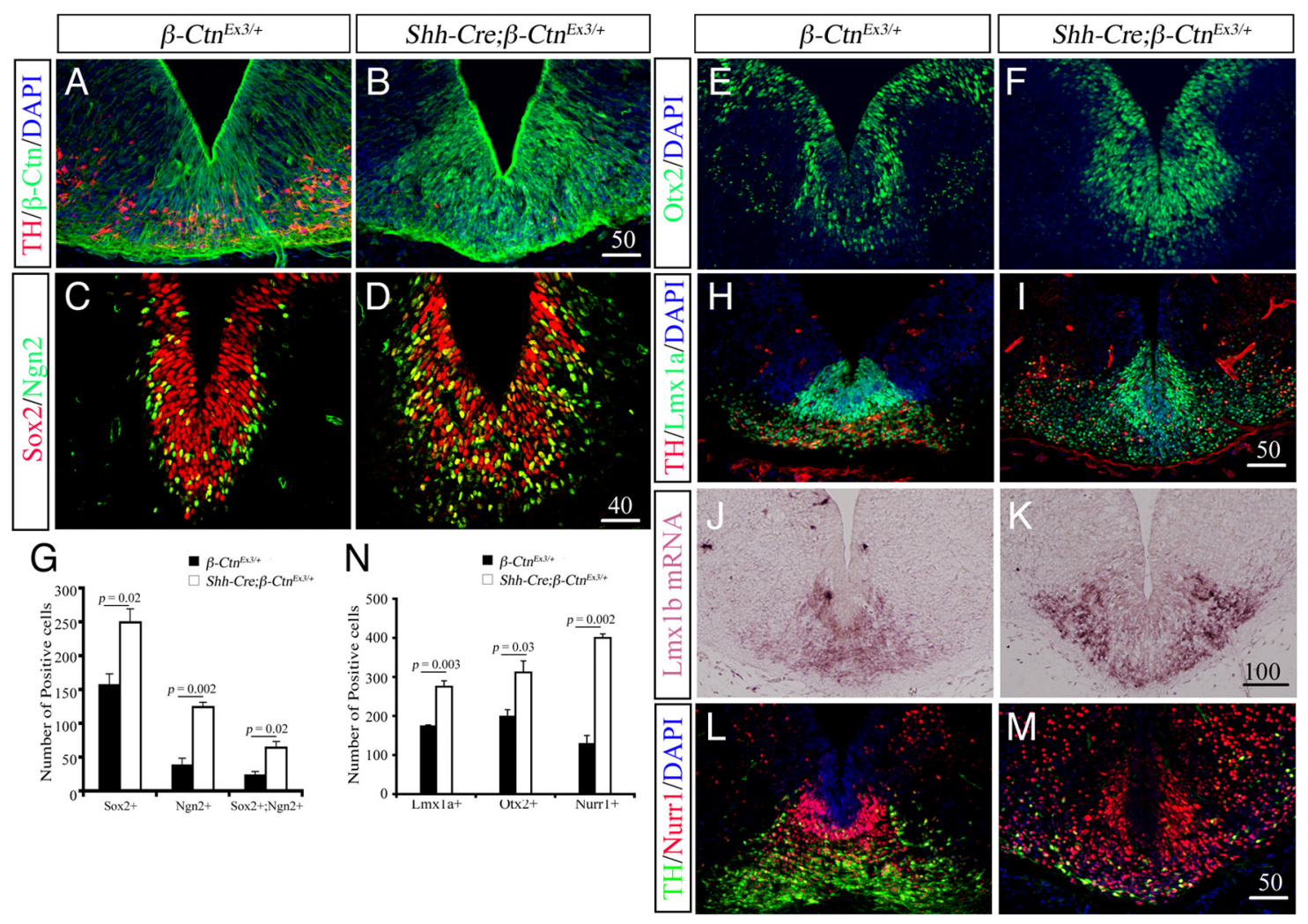

Figure 1. Stabilization of $\beta$-catenin in vMB leads to expansion of DA progenitors. $A, B, \beta$-Catenin staining in the vMB of $\beta$-Ctn ${ }^{E x 3 /+}$ and Shh-Cre; $\beta$ - $C \operatorname{tn}^{E \times 3 /+}$ mice at E12.5. Scale bar (in $\left.\boldsymbol{B}\right), 50$ $\mu \mathrm{m} . \boldsymbol{C}, \boldsymbol{D}$, Immunofluorescent staining at E12.5 shows significant increases in the numbers of $\mathrm{Sox} 2^{+}, \mathrm{Ngn2} 2^{+}$, and Sox2 ${ }^{+} ; \mathrm{Ngn2}{ }^{+}$progenitor at E12.5. $\boldsymbol{E}-\boldsymbol{N}$, In addition, the number of $0 \mathrm{tx} 2^{+}(\boldsymbol{E}$, $\boldsymbol{F}), \mathrm{Lmx}_{1 \mathrm{a}}{ }^{+}(\boldsymbol{H}, \boldsymbol{I}), \mathrm{Lmx}_{\mathrm{b}} \mathrm{b}^{+}(\boldsymbol{J}, \boldsymbol{K})$, and Nurr1 ${ }^{+}(\boldsymbol{L}, \boldsymbol{M})$ progenitors are all increased in Shh-Cre; $\beta$-Ctn ${ }^{E x /++}$ mutants. Scale bars: $\boldsymbol{D}, 40 \mu \mathrm{m} ; \boldsymbol{I}, 50 \mu \mathrm{m} ; \boldsymbol{K}, 100 \mu \mathrm{m} ; \boldsymbol{M}, 50 \mu \mathrm{m} . \boldsymbol{N}, \mathbf{Q u a n t i f i c a t i o n s ~ o f ~}$ $\mathrm{Lmx1a}^{+}, 0 \mathrm{tx2}{ }^{+}$, and Nurr ${ }^{+}$cells show a consistent increase of these progenitors in Shh-Cre; $\beta$-Ctn ${ }^{E \times 3 /+}$ mutants. The data are represented as number of positive cells per section as described previously (Tang et al., 2009). DAPI, 4',6' -Diamidino-2-phenylindole.

After $5 \mathrm{~d}$, medium was changed and supplemented with $25 \mathrm{ng} / \mathrm{ml}$ FGF8 (R \& D Systems) and different concentrations of Shh (R \& D Systems) and the GSK3 $\beta$ inhibitor CT99021. From day 8 to day 11, cells were cultured in N2 medium consisting of F-12 and MEM mixture at 1:1 (Invitrogen), glucose, N2 supplement (Invitrogen), 15 mм HEPES (Invitrogen), $200 \mathrm{~mm}$ L-glutamine, and $3 \mathrm{mg} / \mathrm{ml}$ AlbuMax I (Invitrogen) supplemented with $50 \mathrm{ng} / \mathrm{ml} \mathrm{FGF8} \mathrm{and} 10 \mathrm{ng} / \mathrm{ml} \mathrm{FGF2} \mathrm{(R} \mathrm{\&} \mathrm{D} \mathrm{Systems)}$ and the same concentration of Shh and CT99021 as in days 5-8. From day 11 to day 14 , the media was replaced with $\mathrm{N} 2$ medium supplemented with $30 \mathrm{ng} / \mathrm{ml}$ brain-derived neurotrophic factor (BDNF), $30 \mathrm{ng} / \mathrm{ml}$ glial derived neurotrophic factor (GDNF) (both from R \& D Systems), and $200 \mu \mathrm{M}$ ascorbic acid (Sigma).

After in vitro differentiation, cells were fixed in $4 \%$ PFA (10', RT), serum blocked, and incubated in the appropriate primary and subsequently secondary antibodies as described previously (Parish et al., 2005). Nuclear counterstaining was performed using Hoechst. The following antibodies were used: mouse monoclonal anti-III-tubulin (TuJ1; 1:500; Promega), rabbit polyclonal anti-tyrosine hydroxylase (1:500; PelFreez Biologicals), mouse monoclonal anti-tyrosine hydroxylase (1:500; ImmunoStar), rabbit anti-Foxa2 (1:500; Cell Signaling Technology), rabbit anti-Pitx3 (1:100; Zymed Laboratories), rabbit anti-Nurr1 (1:500; Santa Cruz Biotechnology), and Alexa Fluor 488 goat anti-mouse and Alexa Fluor 555 donkey anti-rabbit (1:500; Invitrogen).

Statistical analyses. Data were analyzed by two-tailed Student's $t$ test. Values were expressed as mean \pm SEM. Changes were identified as significant if the $p$ value was $<0.05$.

\section{Results}

Activation of $\mathrm{Wnt} / \boldsymbol{\beta}$-catenin in vMB leads to expansion of DA progenitors but reduces DA neurogenesis

To determine whether activation of canonical $\mathrm{Wnt} / \beta$-catenin signal in vMB affects the development of DA neurons, we gener- ated conditional mutant mice in which the floxed exon 3 of $\beta$-catenin $\left(\beta-C t n^{E X 3}\right)$ was removed using Shh-Cre (named Shh$\left.C r e ; \beta-C t n^{E x 3 /+}\right)$. Expression of one copy of $\beta-C t n^{E X 3}$ allele using $\mathrm{Sh} h-\mathrm{Cr}$ leads to perinatal lethality as a result of a robust gain-offunction phenotype in multiple organs, including limbs (supplemental Fig. S1, available at www.jneurosci.org as supplemental material). Consistent with the anticipated recombination of ShhCre (Tang et al., 2009), Shh-Cre; $\beta-C t n^{E \times 3 /+}$ mutants showed a much higher level of $\beta$-catenin protein in vMB at E12.5, with a significant accumulation of the mutant proteins in the nuclei of the neural progenitors (Fig. $1 A, B$ ) (data not shown). Compared with control $\left(\beta-C t n^{E x 3 /+}\right)$ embryos, the vMB of Shh-Cre; $\beta$ $C t n^{E x 3 /+}$ embryos showed a marked expansion of Sox2-, Ngn2-, and Otx2-positive progenitors in the ventricular zone (VZ) (Fig. $1 C-G)$. In addition, DA progenitors expressing Lmx1a, Lmx1b, and Nurr1 also showed significant increases in the intermediate zone and marginal zone (Fig. $1 \mathrm{H}-\mathrm{N}$ ).

We next examined whether the constitutive activation of Wnt/ $\beta$-catenin in vMB could have altered cell cycle progression in DA progenitors, as described previously for Wnt 1 in the neural tube (Megason and McMahon, 2002). To test this hypothesis, we performed a short-term ( $2 \mathrm{~h}$ ) BrdU labeling to determine the number of progenitors in the $S$ phase of cell cycle. Although E10.5 and E11.5 Shh-Cre; $\beta-C t n^{E x 3 /+}$ mutants showed no detectable difference in the number of $\mathrm{BrdU}^{+}$progenitors in the $\mathrm{vMB} \mathrm{VZ}$ (Fig. 2A-D), a significant increase was detected at E12.5 (Fig. $2 E, F, M)$. Furthermore, a longer BrdU labeling time interval $(24 \mathrm{~h})$ showed an even more drastic increase in the number of progenitors that incorporated BrdU (Fig. $2 G, H, N$ ). In contrast, 


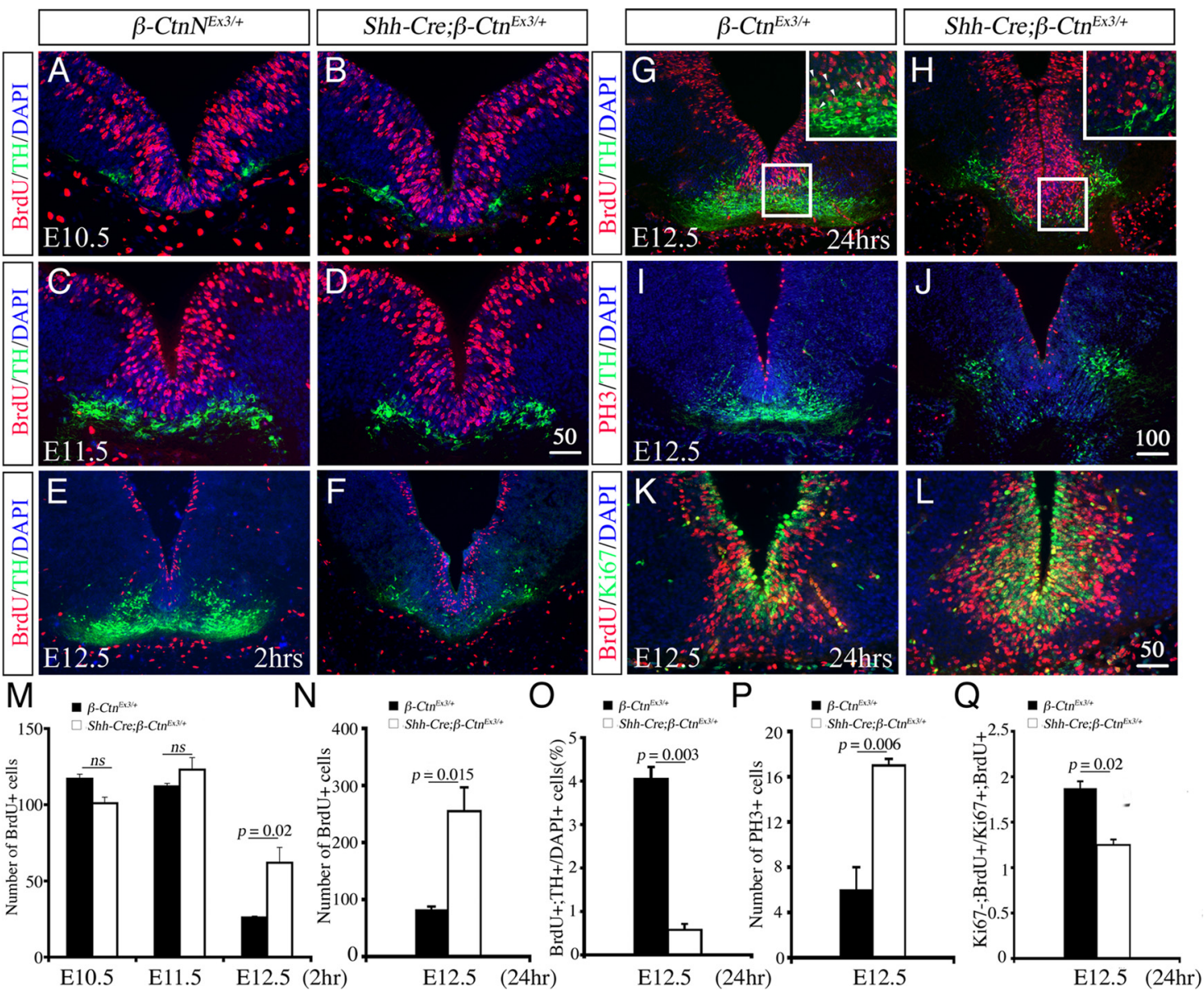

Figure 2. Cell cycle progression of the DA progenitors in vMB of Shh-Cre; $\beta$-Ct ${ }^{E x 3 /+}$ mutants. $A-F$, Stabilization of $\beta$-catenin in vMB results in increased proliferation in early progenitors $(2 \mathrm{~h}$ BrdU injection scheme) in the ventricular zone at E12.5 $(\boldsymbol{E}, \boldsymbol{F})$ but not at E10.5 and E11.5 $(\boldsymbol{A}-\boldsymbol{D})$. Student's $t$ test $(n=3)$; $\mathrm{ns}$, Not significant. $\boldsymbol{G}, \boldsymbol{H}$, Neuronal birthdating experiments using a $24 \mathrm{~h}$ BrdU injection scheme also reveal a robust increase in $\mathrm{BrdU}^{+}$cells in vMB. However, there is a reduction in newly born DA neurons, highlighted by BrdU and TH double-positive $\left(B r d U{ }^{+} ; \mathrm{TH}^{+}\right)$cells in Shh-Cre; $\beta$ - $C \operatorname{tn}^{E \times 3 /+}$ mutants (arrowheads in the insets). I, J, Similarly, the number of PH3 ${ }^{+}$progenitors also increase in Shh-Cre; $\beta$ - $\operatorname{Ct}{ }^{E \times 3 /+}$ mutants. Scale bars: (in $\left.\boldsymbol{D}\right) \boldsymbol{A}-\boldsymbol{D}, 50 \mu \mathrm{m}$; (in $\left.\boldsymbol{J}\right) \boldsymbol{E}-\boldsymbol{J}$, $100 \mu \mathrm{m} . \boldsymbol{K}, \boldsymbol{L}$, Cell cycle exit experiments show that fewer progenitor cells exit cell cycle in $\operatorname{Sh} h-C r e ; \beta$-Ctn ${ }^{E x 3 /+}$ mutants. Scale bar (in $\boldsymbol{L}$ ): $\boldsymbol{K}, \boldsymbol{L}, 50 \mu \mathrm{m} . \boldsymbol{M}-\boldsymbol{Q}, \mathbf{Q u a n t i f i c a t i o n}$ results confirm the increases in $\mathrm{BrdU}{ }^{+}$progenitors $\left(2\right.$ and $24 \mathrm{~h}$ injection schemes) $(\boldsymbol{M}, \boldsymbol{N})$, the reduced production of $\mathrm{BrdU}{ }^{+} ; \mathrm{TH}^{+}$neurons $(\boldsymbol{O})$, the increase in $\mathrm{PH} 3^{+}$progenitors $(\boldsymbol{P})$, and the decrease in cell cycle exit (Q) after the activation of $\beta$-catenin in vMB.

much fewer BrdU and TH double-positive neurons were generated in the $S h h-C r e ; \beta-C t n^{E x 3 /+}$ mutants within the same time interval (Fig. 2G,H, insets, $O$ ). Many of the apical progenitors in the VZ of Shh-Cre; $\beta-C t n^{E x 3 /+}$ mutants continued to show positive $\mathrm{PH} 3$ staining, indicating that they were in the $\mathrm{M}$ phase of cell cycle (Fig. $2 I, J, P$ ). The increases of progenitors in $S$ and $M$ phases of cell cycle in the vMB of Shh-Cre; $\beta-C t n^{E x 3 /+}$ mutants at E12.5 suggested that the constitutive activation of $\mathrm{Wnt} / \beta$-catenin signaling may affect the cell cycle progression in DA progenitors. To address this, we performed birthdating of DA neurons by pulse labeling the progenitors with BrdU for $24 \mathrm{~h}$ and then determined the number of progenitors that have exited cell cycle [BrdUpositive; Ki67-negative $\left(\mathrm{BrdU}^{+} ; \mathrm{Ki}^{-}\right)$] within this time interval. Consistent with our prediction, there were much fewer progenitors in the vMB of Shh-Cre; $\beta-\mathrm{Ctn}^{\mathrm{Ex} 3 /+}$ mutants that have exited the cell cycle during the $24 \mathrm{~h}$ time interval (Fig. $2 K, L, Q$ ). Together, these results supported the notion that constitutive activation of $\mathrm{Wnt} / \beta$-catenin signal in vMB led to the expansion DA progenitors by reducing their exit from the cell cycle.

In analyzing the phenotype of the constitutive activation of Wnt/ $\beta$-catenin signaling in DA progenitors, we noticed that the number of newly born DA neurons, marked by TH-positive staining, was reduced in the vMB of Shh-Cre; $\beta-C t n^{E \times 3 /+}$ mutants at E12.5 (Fig. $2 \mathrm{E}-\mathrm{H}$ ). To provide a more quantitative analysis of DA neurons in Shh-Cre; $\beta-C t n^{E \times 3 /+}$ mutants, we used stereology to determine the total number of DA neurons in vMB from E12.5 to E18.5. Our results showed that, compared with control littermates, there were consistently fewer DA neurons in the vMB of Shh-Cre; $\beta-C t n^{E x 3 /+}$ mutants (Fig. $3 A-G$ ). Interestingly, a small ectopic cluster of DA neurons was identified the interpeduncular nucleus (Fig. 3D,F). At E18.5, the reduction in DA neurons was more prominent in the SNpc compared with the VTA (Fig. 3E-G).

To characterize the reduced DA neuron phenotype in Shh$C r e ; \beta-C t n^{E x 3 /+}$ mutants, we first determined whether there was an increase in cell death. Using activated caspase 3 as a marker, we found no detectable increase in cell death in the vMB of Shh-Cre; $\beta-C t n^{E x 3 /+}$ mutants (supplemental Fig. S2, available at www. jneurosci.org as supplemental material). We next examined whether the ability of DA progenitors to differentiate was impaired in $S h h-C r e ; \beta-C t n^{E x 3 /+}$ mutants. To test this hypothesis, we cultured vMB progenitors from E12.5 control and Shh-Cre; $\beta-C t n^{E x 3 /+}$ embryos in conditions that have been shown previously to promote differentiation of DA neurons (Takeshima et al., 1996; Ye et al., 1998; Schulte et al., 2005). Consistent with the in vivo phenotype, progenitors from Shh-Cre; $\beta-C t n^{E x 3 /+} \mathrm{mu}-$ 


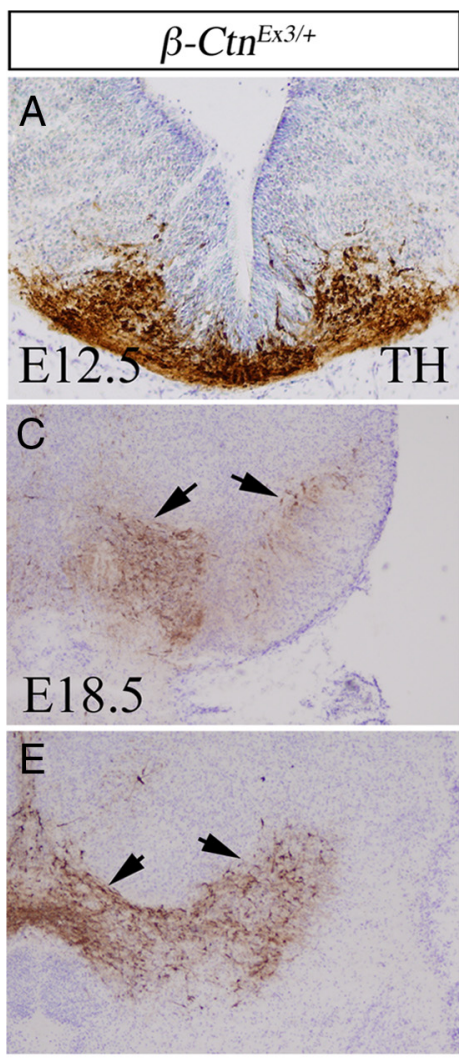

G
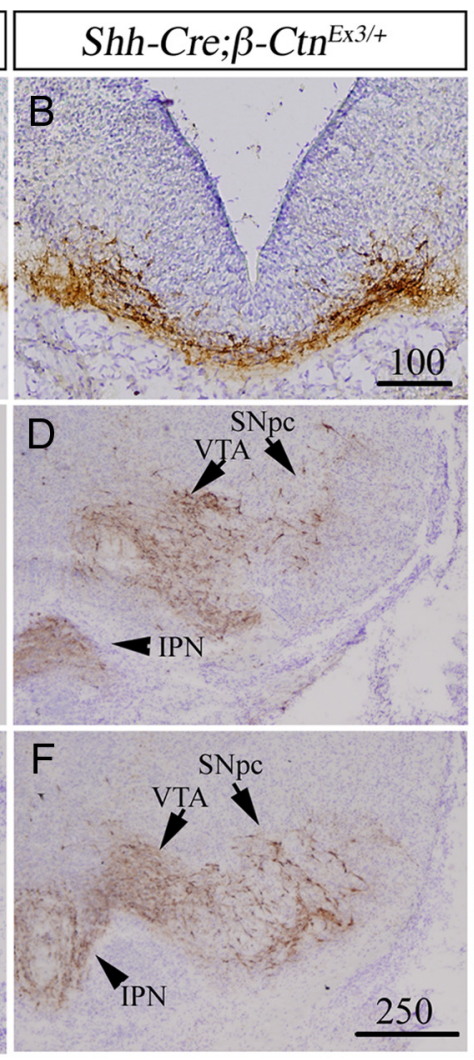
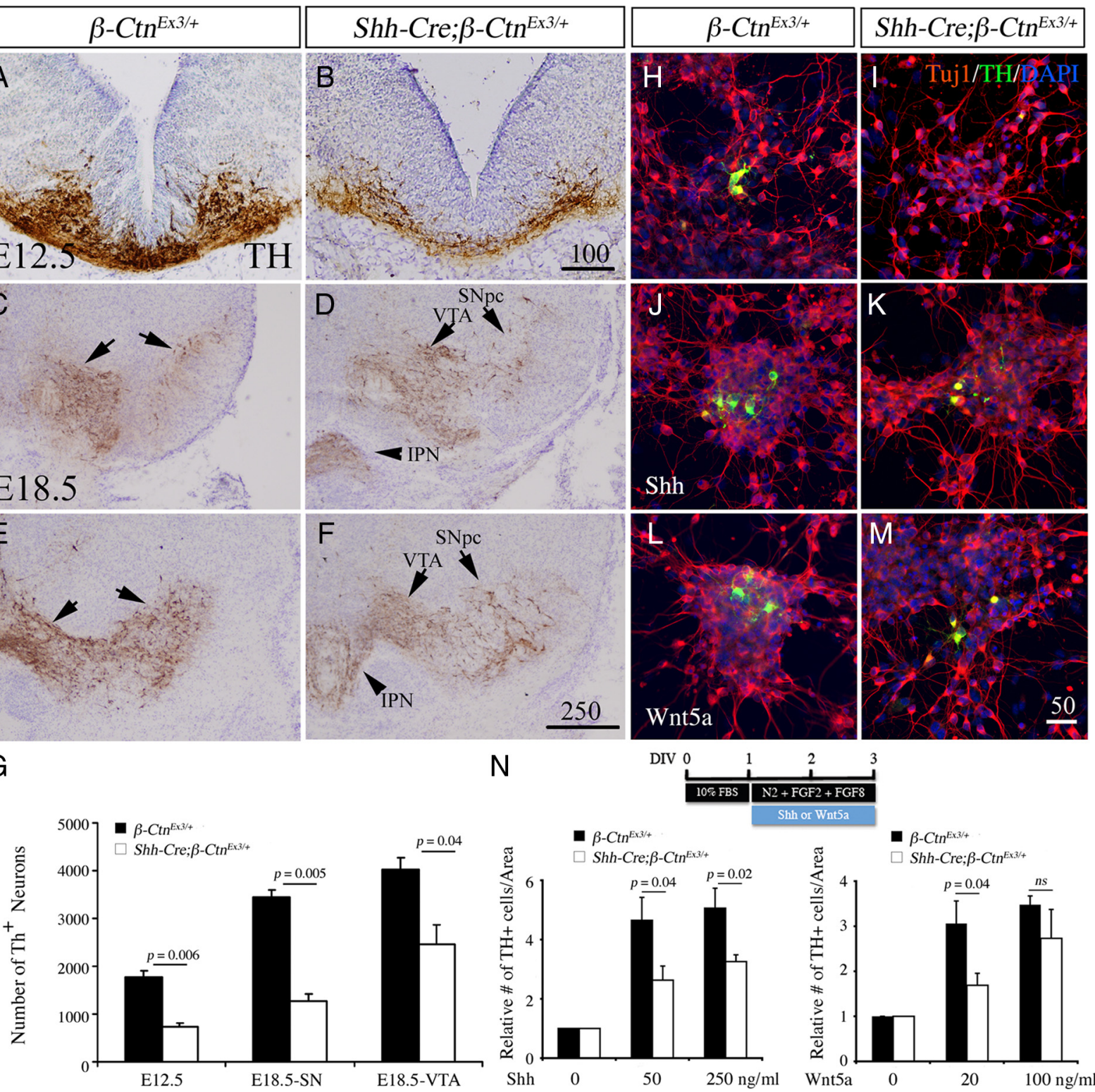

Figure 3. Ventral midbrain progenitors in Shh-Cre; $\beta-C t n^{E \times 3 /+}$ mutants show a significant reduction in DA neurons in vivo and in vitro. $\boldsymbol{A}-\boldsymbol{F}$, Compared with $\mathrm{Control}\left(\boldsymbol{\beta}-\mathrm{Ct}{ }^{\mathrm{Ex} /+}\right)$, vMB of Shh-Cre; $\beta$-Ctn ${ }^{E \times 3 /+}$ mutants show much fewer DA neurons at E12.5 (A, $\left.\boldsymbol{B}\right)$ and E18.5 (C-F). Scale bars: (in $\left.\boldsymbol{B}\right), \boldsymbol{A}, \boldsymbol{B}, 100 \mu \mathrm{m}$; (in $\left.\boldsymbol{F}\right) \boldsymbol{C}-\boldsymbol{F}, 250 \mu \mathrm{m}$. IPN, Interpeduncular nucleus. $\mathbf{G}, \mathbf{Q}$ uantification by stereology confirms the reduced number of DA neurons at E12.5 and P0. Student's $t$ test, $n=3$. $\boldsymbol{H}$-M, Progenitors derived from the vMB of control $\left(\beta-C t n^{E \times 3 /+}\right)$ and Shh-Cre; $\beta$-Ctn ${ }^{E \times 3 /+}$ mutants can be differentiated into DA neurons during the addition of Shh $(\boldsymbol{J}, \boldsymbol{K})$ and Wnt5a $(\boldsymbol{L}, \boldsymbol{M})$. Scale bar (in $\boldsymbol{M}): \boldsymbol{H}-\boldsymbol{M}, 50 \mu \mathrm{m}$. $\boldsymbol{N}$, However, the relative number of TH ${ }^{+}$cells per areas observed in $\mathrm{Shh}-\mathrm{Cre} ; \beta-\mathrm{Ctn}{ }^{\mathrm{Ex} /+}$ mutants are significantly less in the presence of Shh (left) but similar to control at higher concentration of Wnt5a (100 $\mathrm{ng} / \mathrm{ml}$ ) (right). Culture scheme is shown on the top of $\boldsymbol{N}$. The numbers of $\mathrm{TH}^{+}$neurons per area are normalized to control for each genotype. Student's $t$ test $(n=3)$; ns, Not significant. DIV, days in vitro.

tants gave rise to fewer number of DA neurons under basal culture conditions (Fig. $3 H, I)$. Interestingly, the addition of increasing doses of Shh only promoted a very modest increase in the number of DA neurons in progenitors from Shh-Cre; $\beta$ $C t n^{E x 3 /+}$ mutants (Fig. $3 J, K, N$ ). However, when treated with Wnt5a, progenitors from Shh-Cre; $\beta-C t n^{E x 3 /+}$ mutant embryos showed an increase in DA neuron numbers in a manner similar to those from control (Fig. $3 L-N)$.

\section{Activation of Wnt/ $\boldsymbol{\beta}$-catenin antagonizes expression of Shh and Shh targets in vMB}

The results from Figure 3 supported the notion that treatments with additional exogenous factors, such as Shh or Wnt5a, can indeed promote the generation of DA neurons from the progenitors of $S h h-C r e ; \beta-C t n^{E x 3 /+}$ mutants. However, the fewer num- ber of DA neurons from Shh-Cre; $\beta-C t n^{E x 3 /+}$ mutants suggested that the regional activation of canonical $\mathrm{Wnt} / \beta$-catenin signal may have altered the milieu in the neurogenic niche of DA neurons or the intrinsic properties of DA progenitors in Shh-Cre; $\beta$ $C t n^{E \times 3 /+}$ mutants. To test these hypotheses, we examined Shh expression, an important exogenous factor that regulates the neurogenesis of DA neurons (Hynes et al., 1995). Our results showed that $S h h$ mRNA was diffusely expressed in the floor plate at E10.5 (Fig. 4A). By E12.5, Shh mRNA became more restricted to the $\mathrm{VZ}$ of $\mathrm{VMB}$, immediately adjacent to the neurogenic niche of DA progenitors (Fig. 4C). Despite the restricted expression pattern of Shh mRNA, Shh proteins were more widespread in the $\mathrm{vMB}$, extending from VZ to the pia surface, suggesting that Shh proteins may be transported along the radial glia (Fig. $4 E$ ). This was confirmed by confocal imaging, which showed an extensive 

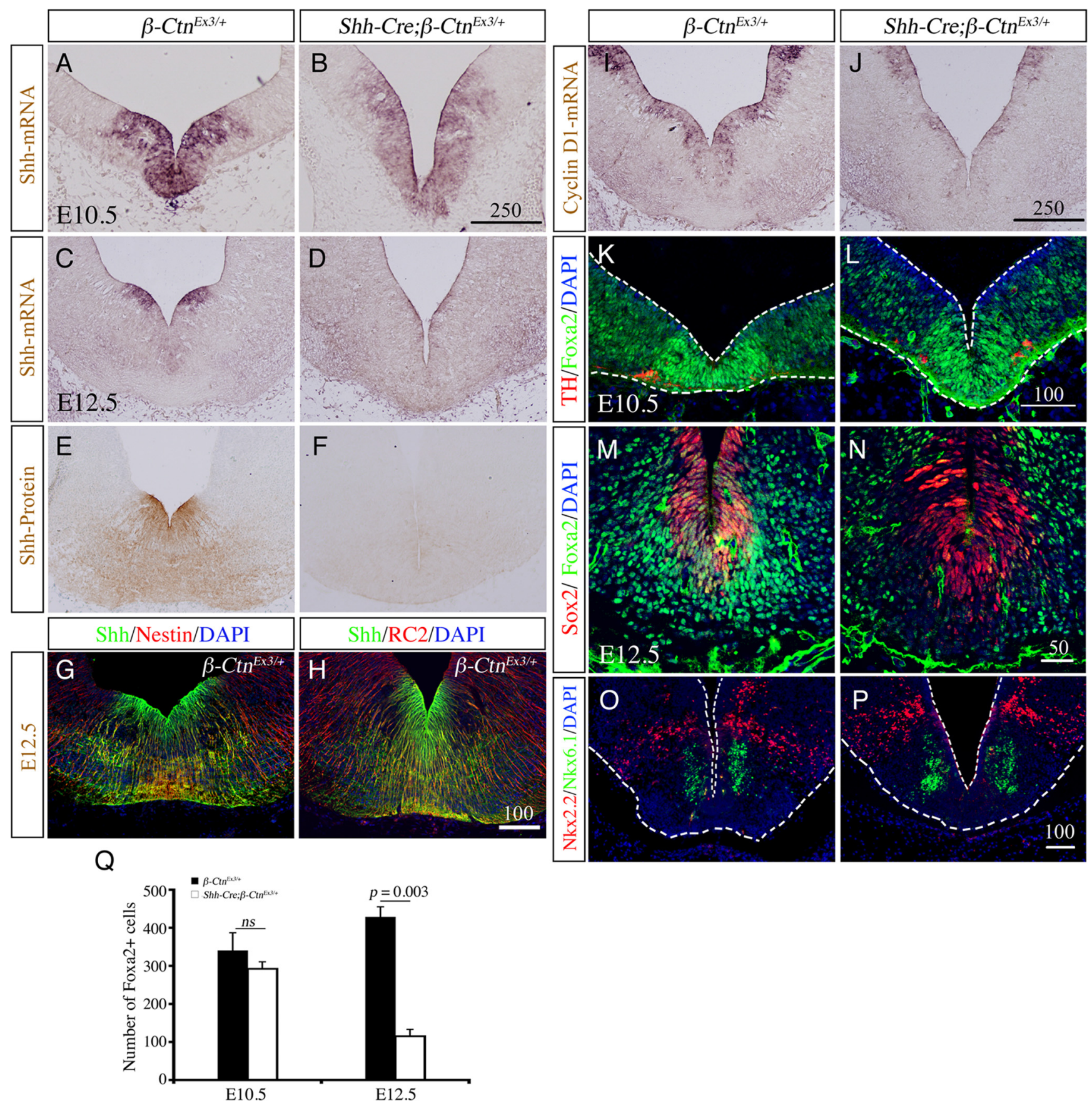

Figure 4. Activation of $\beta$-catenin in vMB antagonizes Shh expression and reduces Shh target genes. $\boldsymbol{A}, \boldsymbol{B}$, Shh mRNA expression is slightly reduced at E10.5 in vMB of $\operatorname{Shh}-\mathrm{Cre} ; \beta$-Ctn ${ }^{E \times 3 /+}$ mutants. Scale bar (in $\boldsymbol{B}): \boldsymbol{A}, \boldsymbol{B}, 250 \mu \mathrm{m}$. $\boldsymbol{C}-\boldsymbol{F}, \mathrm{By}$ E12.5, Shh mRNA $(\boldsymbol{C}, \boldsymbol{D})$ and protein $(\boldsymbol{E}, \boldsymbol{F})$ expression are severely reduced in the vMB of Shh-Cre; $\beta$-Ctnn ${ }^{E x 3 /+}$ mutants. $\boldsymbol{G}, \boldsymbol{H}, \mathrm{Tw}$ representative images show the extensive colocalization of Shh (green) and the radial glia marker Nestin (red) (G) and Shh and RC-2 (H). Scale bar: $\boldsymbol{H}, 100 \mu \mathrm{m} . \boldsymbol{I}, \boldsymbol{J}$, Shh downstream target gene cyclin D1 show a similar reduction in the vMB of Shh-Cre; $\beta$-Ctn ${ }^{E \times 3 /+}$ mutants. Scale bar (in $\left.\boldsymbol{J}\right): \mathbf{C}-\boldsymbol{H}, 250 \mu \mathrm{m} . \boldsymbol{K}-\boldsymbol{N}$, Compared with control $\left(\beta-\left(\mathrm{Cn}^{\mathrm{Ex} 3 /+}\right)\right.$, another Shh target Foxa2 shows no detectable reduction in Shh-Cre; $\beta$-Cth ${ }^{E \times 3 /+}$ mutants at E10.5 $(\boldsymbol{K}, \boldsymbol{L})$ but is significantly downregulated at E12.5 $(\boldsymbol{M}, \boldsymbol{N})$. Scale bars: $\boldsymbol{L}, 100 \mu \mathrm{m} ; \boldsymbol{N}, 50 \mu \mathrm{m} . \mathbf{0}, \boldsymbol{P}$, In contrast, expression of Nkx6.1 and Nkx2.2 in vMB shows no detectable changes in Shh-Cre; $\beta$-Ctn ${ }^{E \times 3 /+}$ mutants. Scale bar: $\boldsymbol{N}, 100 \mu \mathrm{m}$. Q, Quantification of Foxa2 ${ }^{+}$progenitors at E10.5 and E12.5. Student's $t$ test $(n=3)$. ns, Not significant.

colocalization of Shh proteins with radial glia markers, e.g., Nestin, RC-2, and Glast (glutamate-aspartate transporter) (Fig. $4 G, H$ and data not shown). Unlike the wild-type embryos, constitutive activation of Wnt $/ \beta$-catenin led to a modest decrease of Shh mRNA at E10.5 (Fig. $4 B$ ) but a near complete loss of Shh protein and mRNA in the vMB of Shh-Cre; $\beta-\mathrm{Ctn}^{\mathrm{Ex3} /+}$ mutants at E12.5 (Fig. 4D, F). Consistent with these results, the expression of Shh targets, such as cyclin D1 and Foxa2, was reduced in the vMB of Shh-Cre; $\beta-C t n^{E \times 3 /+}$ mutants at E12.5 but not at E10.5 (Fig.
$4 I-N)$. In contrast, the expression of other regional vMB markers, such as Nkx2.2 and Nkx6.1, showed no detectable change (Fig. 4O,P). These results supported the hypothesis that persistent activation of Wnt $/ \beta$-catenin could alter the neurogenic niche for DA neurons by antagonizing the expression of Shh and Shh target genes in the progenitors.

To further characterize the interactions between canonical Wnt/ $\beta$-catenin and Shh in the generation of DA neurons, we cultured progenitors from the vMB of wild-type E10.5 embryos 
A

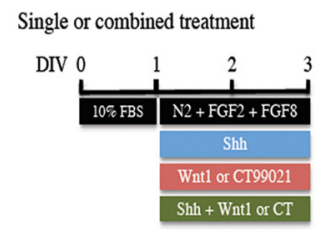

Sequential treatment DIV 0
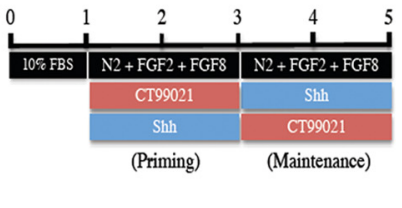
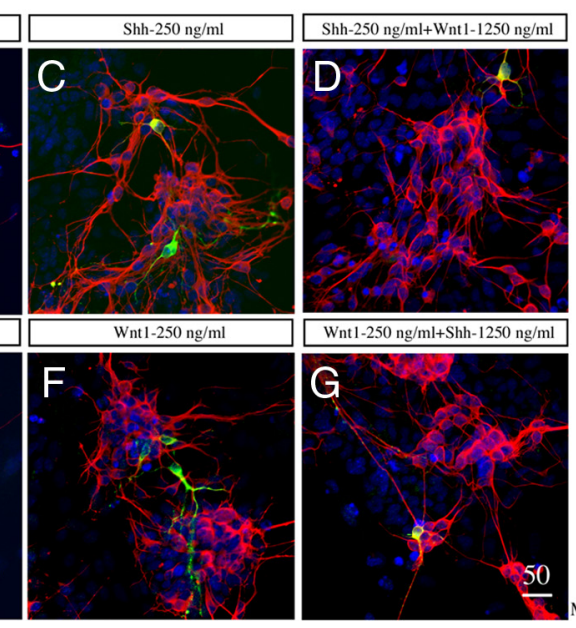
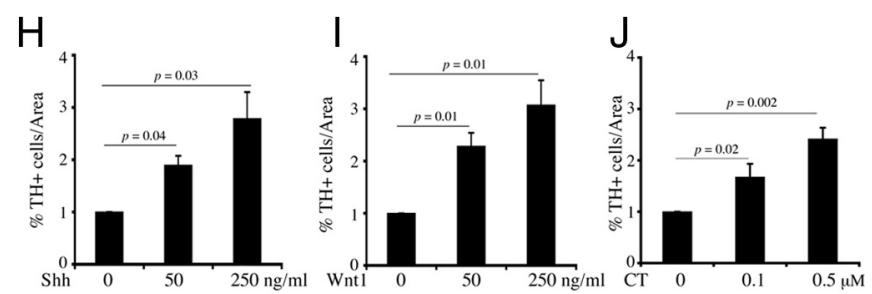

\section{$\mathrm{K}$}

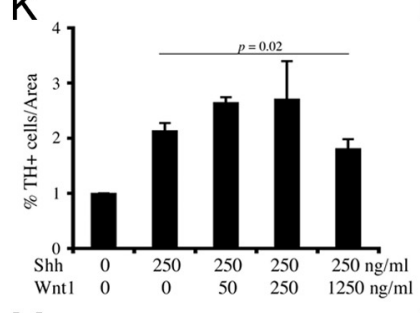

L
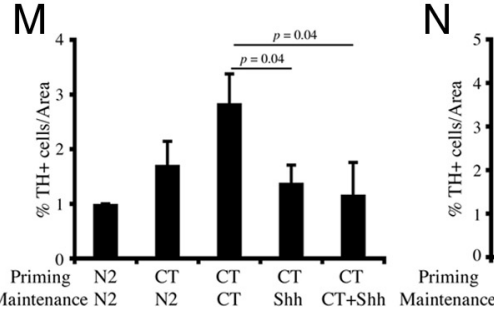

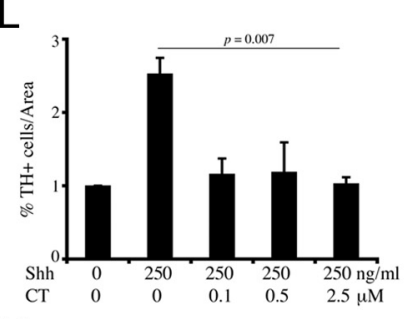

$\mathrm{N}$

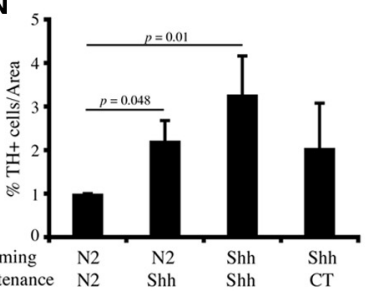

Figure 5. Ventral midbrain progenitor cultures show antagonistic effect between canonical Wnt/ $\beta$-catenin signaling and Shh. $\boldsymbol{A}$, Schematic diagrams illustrating the two culture conditions for DA progenitors. In the "single or combined treatment" paradigm, vMB progenitors are treated with Shh, Wnt1, the GSK3 $\beta$ inhibitor CT99021 alone, or with a combination of Shh and Wnt1, or Shh and CT99021 (B- $\boldsymbol{L})$. In the "sequential treatment" paradigm, the vMB progenitors are treated with Shh or (T99021 from day 1 to 3 and then switched to $(T 99021$ or Shh from day 3 to $5(\boldsymbol{M}, \boldsymbol{N})$. $\boldsymbol{B}-\boldsymbol{J}$, Compared with control $(\boldsymbol{B}, \boldsymbol{E})$, treatments with Shh or Wnt1 alone increase the number of DA neurons in a dose-dependent manner, with the maximal effect at $250 \mathrm{ng} / \mathrm{ml}(\boldsymbol{C}, \boldsymbol{F}, \boldsymbol{H}, \boldsymbol{I})$. Similarly, treatments with the GSK3 $\beta$ inhibitor (T99021 can also increase the number of DA neurons $(\boldsymbol{J}) . \boldsymbol{K}, \boldsymbol{L}$, To determine whether simultaneous treatments of Wnt 1 and $S h h$ can maximize the production of DA neurons, we treat the progenitor cultures with optimal concentration of Shh $(250 \mathrm{ng} / \mathrm{ml})$ and increasing amounts of Wnt 1 or CT99021 (D, G, $K, L)$. Combined treatment of Shh and Wnt 1 show a very modest increase in DA neuron number at 50 and $250 \mathrm{ng} / \mathrm{ml} \mathrm{Wnt1} \mathrm{but} \mathrm{not} \mathrm{at} \mathrm{high} \mathrm{dose} \mathrm{(1250} \mathrm{ng} / \mathrm{ml})$. On the contrary, combined treatments of Shh and (T99021 show an antagonistic effect $(n=4)$. Scale bar (in $\mathbf{G}): \boldsymbol{B}-\mathbf{G}, 50 \mu \mathrm{m} . \mathbf{M}, \mathbf{N}$, Compared with single treatment with CT99021 or Shh, sequential treatment of CT99021 and Shh decreases the DA neuron number $(n=3)$.

and treated these progenitors with single, combined, or sequential treatment of Shh, Wnt1, or the GSK3 $\beta$ inhibitor CT99021 (Fig. 5A). Our results showed that treatment of these progenitors with increasing amount of recombinant Wntl or Shh led to a dose-dependent increase in DA neuron numbers, with the optimal concentration at $250 \mathrm{ng} / \mathrm{ml}$ (Fig. $5 B, C, E, F, H, I$ ). Consistent with these results, the selective GSK3 $\beta$ inhibitor CT99021 also promoted the generation of DA neurons (Fig. 5J). Surprisingly, combined treatments of Wnt 1 and Shh did not show an additive or synergistic effect on the generation of DA neurons. Rather, higher doses of Wnt1 $(1250 \mathrm{ng} / \mathrm{ml})$ appeared to reduce DA neuron generation from the progenitors at the optimal condition for Shh $(250 \mathrm{ng} / \mathrm{ml})$ (Fig. $5 K)$. Similarly, the GSK3 $\beta$ inhibitor CT99021 also showed inhibitory effects on the generation of DA neurons in the optimal conditions for Shh $(250 \mathrm{ng} / \mathrm{ml})$ (Fig. $5 L$ ). Such antagonistic effects between Wntl and Shh in the generation of DA neurons were also detected in cultures obtained from the vMB of E13.5 embryos (supplemental Fig. S3, available at www.jneurosci.org as supplemental material).

The lack of additive or synergistic effect between Wnt1 and Shh raised the possibility that a sequential activation of canonical $\mathrm{Wnt} / \beta$-catenin and Shh signaling pathways may be able to better recapitulate the in vivo conditions of DA neurogenesis and maximize the yield of DA neuron generation in cultures. To test this hypothesis, we cultured progenitors from E10.5 embryos and first treated them with optimal concentration of the GSK3 $\beta$ inhibitor CT99021 or Shh (the "priming" stage), followed by switching culture conditions to optimal concentration of Shh or
CT99021 (the "maintenance" stage) (Fig. 5A). Contrary to our expectations, sequential treatments with CT99021 followed by Shh, or Shh followed by CT99021, reduced the number of DA neurons compared with cultures treated with CT99021 or Shh alone (Fig. $5 \mathrm{M}, \mathrm{N})$.

The antagonistic interaction between Shh and Wntl in the generation of DA neurons from stem/progenitor cells was also examined in a previously established culture condition to generate DA neurons from mESCs (Barberi et al., 2003). This culture protocol consisted of a four-step protocol of treating mESCs cocultured with mitomycin-treated stromal cells PA6 in serum replacement media (SRM) (days $0-5$ ), SRM plus FGF8 (days 5-8), N2 media plus FGF8 and FGF2 (days 8-11), and finally N2 media plus ascorbic acid, BDNF, and GDNF (days 11-14) (Fig. $6 A$ ). Under this condition, the majority of the $\mathrm{TH}^{+}$neurons expressed additional dopaminergic markers, including Foxa2, Nurr1, and Pitx3a (supplemental Fig. S4, available at www. jneurosci.org as supplemental material) (Rodríguez-Gómez et al., 2007; Hedlund et al., 2008). These results supported the notion that most $\mathrm{TH}^{+}$neurons derived from mESCs using this protocol exhibited a phenotype consistent with that of vMB DA neurons. Our results also showed that the addition of Shh (200 $\mathrm{ng} / \mathrm{ml}$ ) from days 5 to 11 further promoted the generation of $\mathrm{TH}^{+}$neurons from mESCs (Fig. $6 \mathrm{~B}$ ). Unlike the primary cultures, however, addition of the GSK3 $\beta$ inhibitor CT99021 had no effect on DA neurons (Fig. 6B). Here it is important to note that the baseline generation of DA neurons (and possibly the level of Wnt signaling) in ESC cultures is higher than in progenitors from 


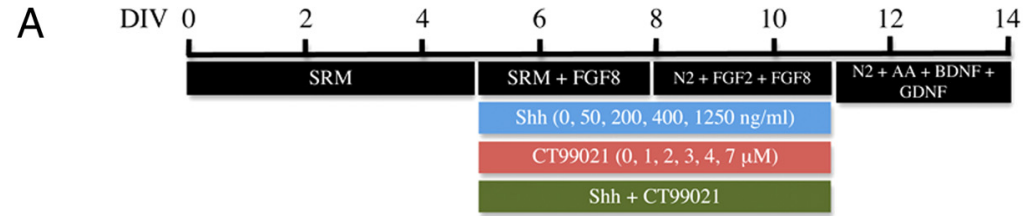

B
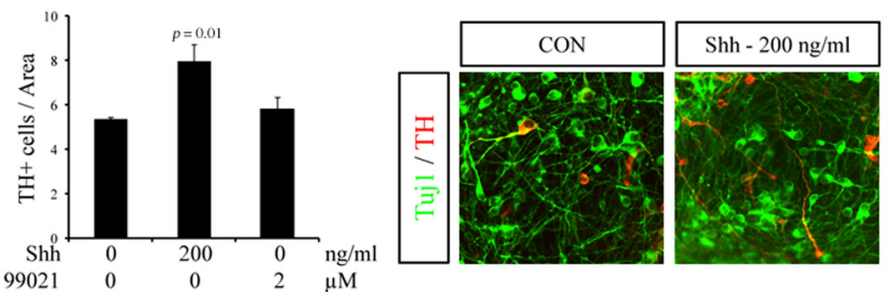

C
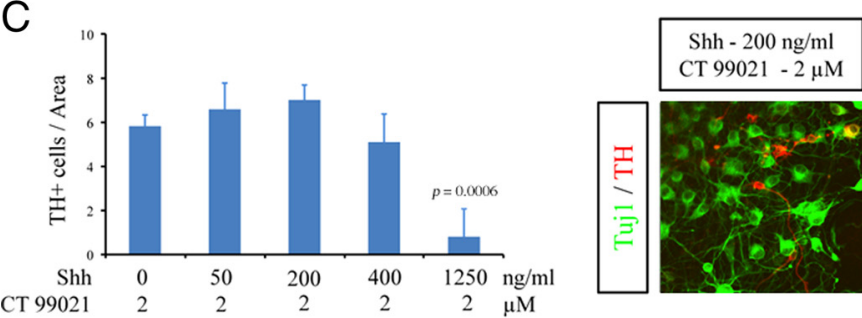

D
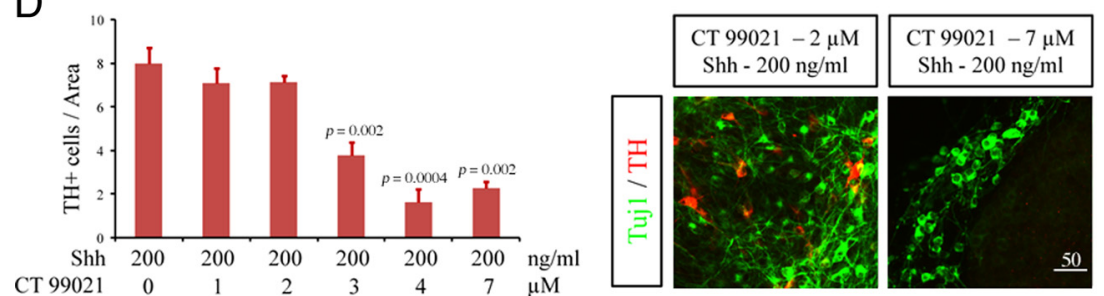

Figure 6. Antagonistic effects between Wnt/ $\beta$-catenin and Shh in generating DA neurons from mESCs. $A$, Schematic diagrams illustrating the culture conditions to generate DA neurons from mESCs. Mouse ESCs are cultured in the presence of SRM, followed by basal conditions, including SRM plus FGF8 (for $3 \mathrm{~d}$ ), SRM plus FGF2 and FGF8 (for $3 \mathrm{~d}$ ), and finally N2 supplement plus ascorbic acid (AA), GDNF, and BDNF (for 3 d). Modified treatment conditions include the addition of Shh, CT99021, or Shh and CT99021 from day 5 to 11. B. Treatment with Shh $(200 \mathrm{ng} / \mathrm{ml})$ or CT99021 (2 $\mu \mathrm{M})$ alone increases the DA neuron numbers. $\boldsymbol{C}$, Combined treatments with Shh and CT99021 do not show additive or synergistic effects in generating more DA neurons from mESCs. In contrast, higher concentration of Shh $(1250 \mathrm{ng} / \mathrm{ml})$ antagonizes the effects of CT99021 on DA neuron yield. $D$, Similarly, the GSK3 $\beta$ inhibitor CT99021 also antagonizes on the effect of Shh in the generation of DA neuron in a range of concentrations $(n=3)$. DIV, Days in vitro; $\mathrm{CON}$, control.

E10.5 embryos. Despite this difference, and similar to the observation in progenitor cultures from E10.5 embryos, combined treatments of Shh and CT99021 did not show additive or synergistic effects (Fig. 6C,D). Rather, higher doses of Shh suppressed DA neurogenesis from mESCs (Fig. 6C), and high doses of CT99021 inhibited the ability of Shh to generate DA from mESCs (Fig. 6D). Moreover, we also found that high doses of CT99021 inhibited overall neurogenesis in most of the colonies, as assessed by a reduction in the number of Tuj $1^{+}$cells. Interestingly, Tuj1positive neurons were mainly detected outside the colonies (Fig. $6 D$, right).

\section{Activation of $\mathrm{Wnt} / \boldsymbol{\beta}$-catenin in midline progenitors promotes DA neurogenesis in vivo}

The results in Shh-Cre; $\beta$-Ctn ${ }^{\mathrm{Ex} 3 /+}$ mutants indicated that the constitutive activation of the canonical Wnt/ $\beta$-catenin signaling in the vMB led to the expansion of DA progenitors but reduced the neurogenesis of DA neurons (Figs. 1, 2). Based on these data, we reasoned that cell-type-specific activation of the $\mathrm{Wnt} / \beta$ catenin signaling in midline progenitors may avoid the defect in
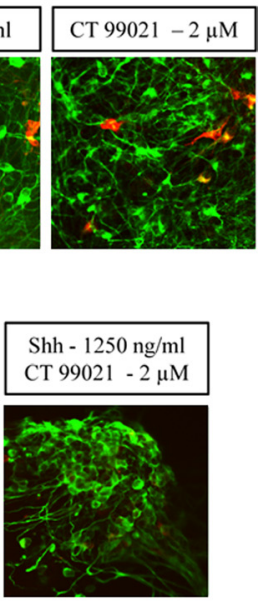

DA neurogenesis seen in Shh-Cre; $\beta-C t$ $n^{E x 3 /+}$ mutants. To test this hypothesis, we generated Th-IRES-Cre; $\beta-C t n^{E x 3 /+} \mathrm{mu}-$ tants. We have shown previously that $T h-$ IRES-Cre mediates recombination in essentially all postmitotic DA neurons and a subpopulation of midline progenitors at E10.5 (Tang et al., 2009). Unlike the phenotype in Th-IRES-Cre; $\beta-C t n^{f l f l}$ mutants, the number of DA neurons in $T h-$ IRES-Cre; $\beta-C t n^{E x 3 /+}$ mutants showed a significant increase at E11.5 and E12.5 (Fig. $7 A-D, I)$. By P0 and P21, Th-IRES-Cre; $\beta$ $\mathrm{Ctn}^{\mathrm{Ex3} /+}$ mutants showed an $\sim 20 \%$ increase in DA neuron numbers compared with controls (Fig. $7 E-I$ ). In addition to the increase in DA neurons, Th-IRES-Cre; $\beta$ $C t n^{E \times 3 /+}$ mutants also showed a persistent increase in the number of committed progenitors (Nurr ${ }^{+} ; \mathrm{TH}^{-}$cells) in vMB at E11.5 and E12.5 (Fig. 7J-N). Furthermore, we performed $24 \mathrm{~h}$ neuronal birthdating experiments by labeling the progenitors with BrdU at E10.5 or E11.5 and allowed them to become $\mathrm{TH}^{+}$postmitotic DA neurons until E11.5 and E12.5, respectively. Our results showed that the number of newly born $\mathrm{TH}^{+}$ neurons was significantly increased in Th-IRES-Cre; $\beta-C t n^{E x 3 /+}$ mutants (Fig. 7O-S).

To further investigate the mechanisms of the increased Nurr1 ${ }^{+} ; \mathrm{TH}^{-}$progenitors in Th-IRES-Cre; $\beta-C t n^{E x 3 /+}$ mutants, we performed birthdating experiments in this population by labeling the progenitors with BrdU at E10.5 or E11.5 and allowed them to develop for $24 \mathrm{~h}$. Our results showed an increase in the number of newly born Nurr1 ${ }^{+}$precursors within the $24 \mathrm{~h}$ time intervals from E10.5 to E11.5 and from E11.5 to E12.5 (Fig. 8A-E). Together, these results indicated that the activation of $\mathrm{Wnt} / \beta$-catenin signaling in a subpopulation of midline progenitors using the Th-IRES-Cre led to a significant increase in neurogenesis and DA neurons.

\section{Discussion}

The results from this study reveal an intricate, albeit primarily antagonistic, interaction between $\mathrm{Wnt} / \beta$-catenin and Shh during DA neurogenesis in vMB progenitors as well as in mESCs (Fig. $8 F)$. Activation of $\mathrm{Wnt} / \beta$-catenin can promote the expansion of DA progenitors and the generation of DA neurons. However, these effects appear to be cell-context dependent such that constitutive activation of $\mathrm{Wnt} / \beta$-catenin in vMB using Shh-Cre expands early progenitors but perturbs cell cycle progression in these progenitors and antagonizes the expression of Shh and Foxa 2 in vMB. These phenotypes contribute to the reduced number of DA neurons. In contrast, a cell-type-specific activation of Wnt/ $\beta$-catenin in the midline progenitors using Th-IRES-Cre circumvents these adverse effects and leads to a significant increase in DA neuron numbers. 

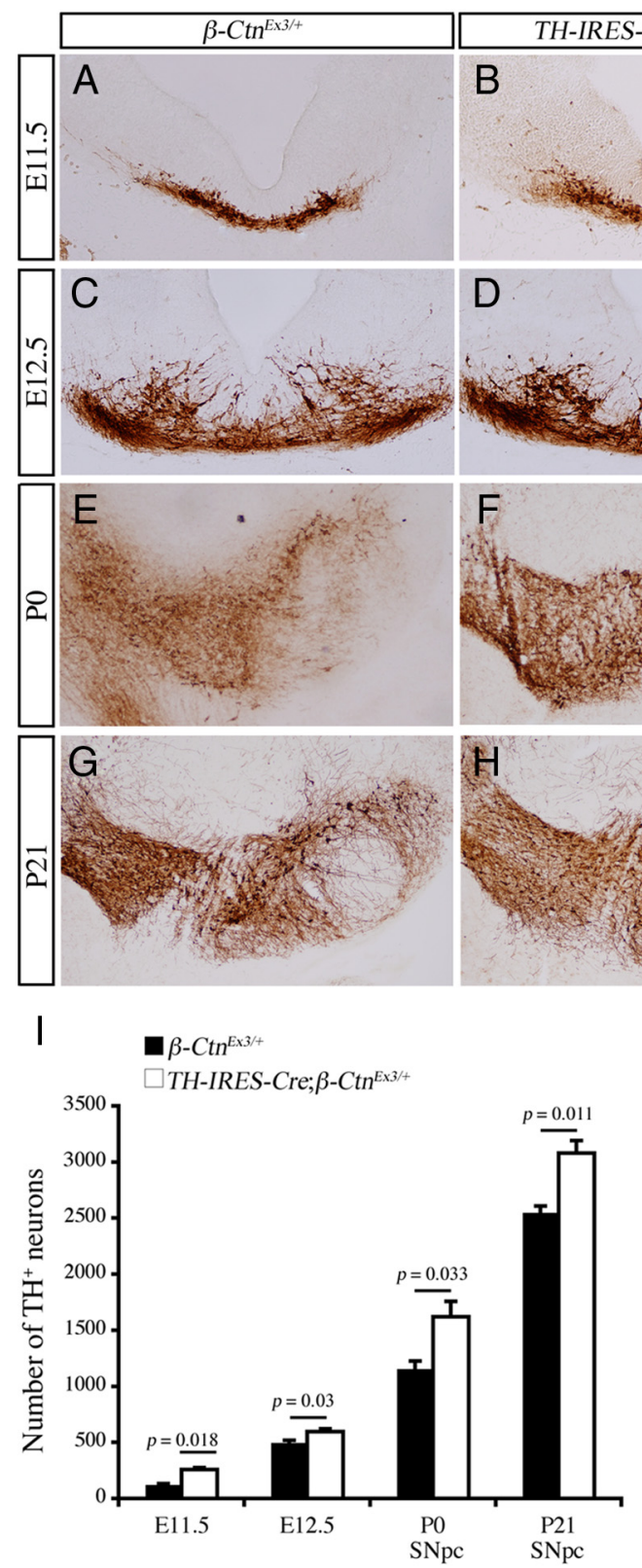
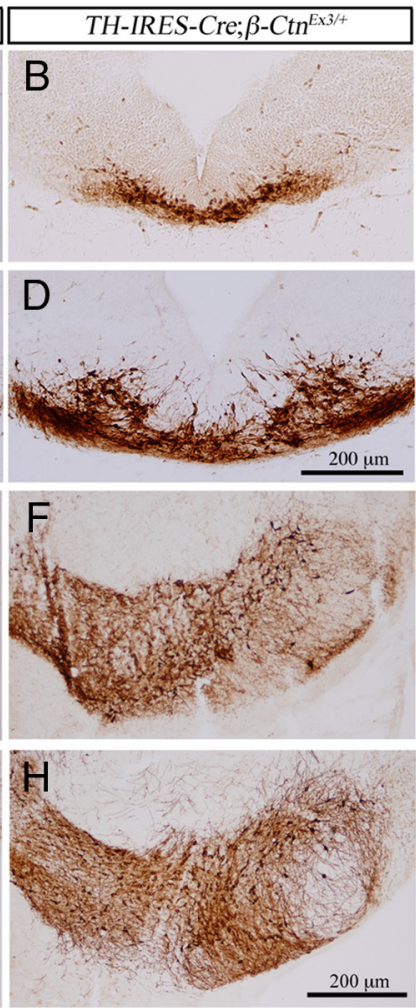

N

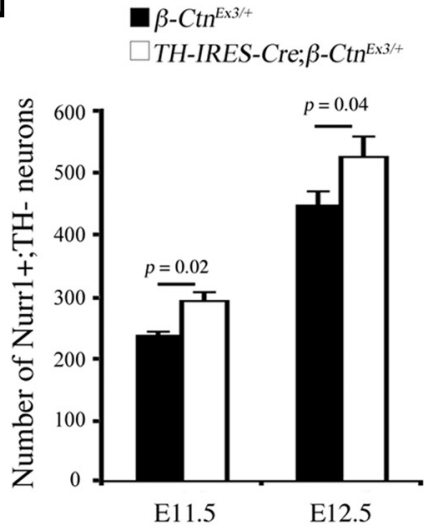

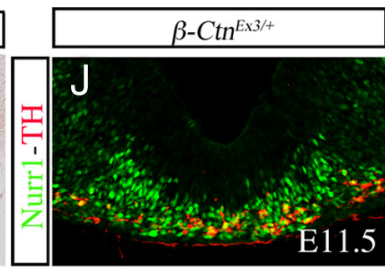

TH-IRES-Cre; $\beta-C$ tn $^{E \times 3 /+}$
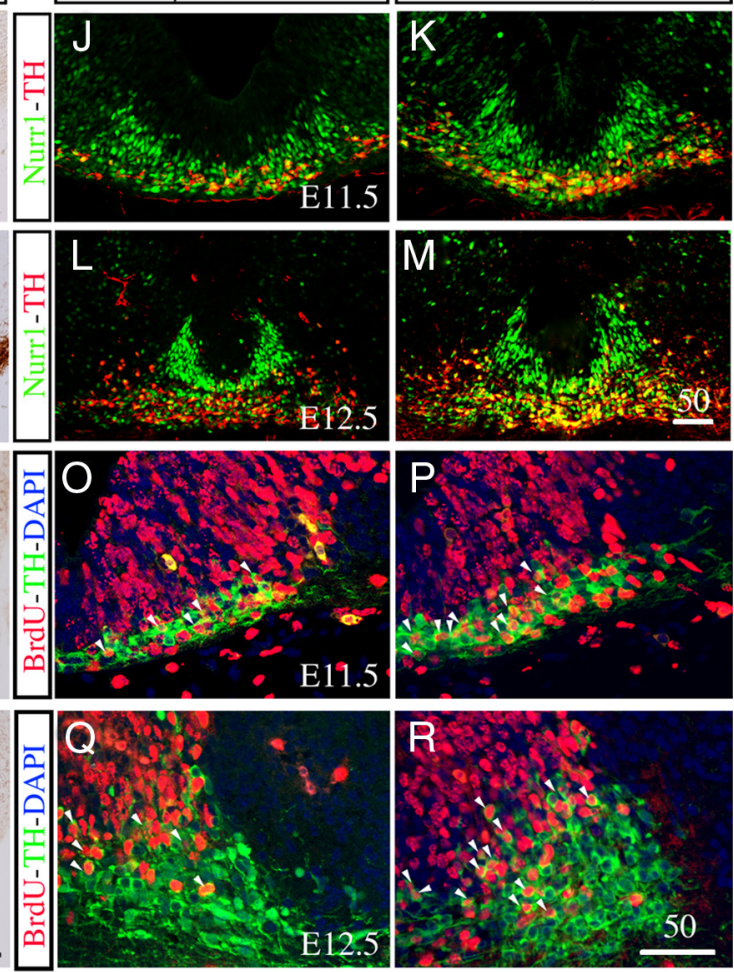

$S$

a $\beta-C \operatorname{tn}^{E \times 3 /+}$

$\square$ TH-IRES-Cre; $\beta-C t n^{E \times 3 /+}$

Figure 7. Increased DA neurons in Th-IRES-Cre; $\beta$-Ctn ${ }^{E x 3 /+}$ mutants. $\boldsymbol{A}-\boldsymbol{H}, \mathrm{Compared}$ with control $\left(\beta-C t n^{E \times 3 /+}\right)$, the number of DA neurons is increased in Th-IRES-Cre; $\beta$-Ctn ${ }^{E \times 3 /+}$ mice at $\mathrm{E} 11.5(\boldsymbol{A}, \boldsymbol{B}), \mathrm{E} 12.5(\boldsymbol{C}, \boldsymbol{D}), \mathrm{PO}(\boldsymbol{E}, \boldsymbol{F})$, and P21 $(\boldsymbol{G}, \boldsymbol{H})$. Scale bars: $\boldsymbol{D}, \boldsymbol{H}, 200 \mu \mathrm{m}$. I, Quantification using stereology confirms the increased number of DA neurons at E11.5, E12.5, P0, and P21. Student's $t$ test, $n=3 . J-M$, Th-IRES-Cre; $\beta$-Ctn ${ }^{E x 3 /+}$ mice show a persistent increase in the number of postmitotic DA precursors (Nurr $1^{+} ; \mathrm{TH}^{-}$) at E11.5 and E12.5. Scale bar: $J-\boldsymbol{M}, 50 \mu \mathrm{m} . \boldsymbol{N}, \mathbf{Q}$ Quantitative analyses for the number postmitotic DA precursors (Nurr1 ${ }^{+} ; \mathrm{TH}^{-}$) at E11.5 and E12.5. $\mathbf{0}-\boldsymbol{R}$, Neuronal birthdating experiments reveal increases of newly generated DA neurons (BrdU ${ }^{+} ; \mathrm{TH}^{+}$) from E10.5 to E11.5 and from E11.5 to E12.5. The arrowheads indicate there are more BrdU ${ }^{+} ; \mathrm{TH}^{+}$cells in the mutants. S, Quantification confirms the increased number of BrdU ${ }^{+} ; \mathrm{TH}^{+}{ }^{+}$cells at E11.5 and E12.5.

Wnt/ $\beta$-catenin signaling and the development of DA neurons Several members of the Wnt family have been shown to regulate distinct aspects of the development of midbrain DA neurons. For instance, the canonical Wnt signaling mechanisms, mediated by Wnt1, Wnt2, and Wnt3a, control the patterning of midbrainhindbrain junction and the initial generation of DA progenitors in $\mathrm{vMB}$, whereas Wnt5a regulates the differentiation of DA neurons (Danielian and McMahon, 1996; Castelo-Branco et al., 2003; Castelo-Branco and Arenas, 2006; Andersson et al., 2008; Sousa et al., 2010). Consistent with these findings, analyses of $W n t 1^{-/-}$and $E n 1^{W n t 1 /+}$ mutant mice reveal a genetic network controlled by Wntl to regulate the establishment of DA progenitor domain and the full differentiation of DA neurons (Prakash et al., 2006; Omodei et al., 2008). Moreover, targeted deletion of $\beta$-catenin using either region-specific Shh-Cre in vMB or celltype-specific Th-IRES-Cre in midline progenitors further demonstrate the essential role of $\mathrm{Wnt} / \beta$-catenin signaling in the control of gene expression and in cell cycle progression during DA neurogenesis (Joksimovic et al., 2009; Tang et al., 2009). Remarkably, the effects of $\mathrm{Wnt} / \beta$-catenin signaling appear to be highly conserved in mESCs in which $\beta$-catenin and Lmxla cooperatively controls the differentiation of DA neurons through an autoregulatory feedback mechanism (Chung et al., 2009). Furthermore, similar roles for $\beta$-catenin have also been demonstrated in the regulation of cell cycle progression in neural progenitors of the ventral telencephalon (Gulacsi and Anderson, 2008). 

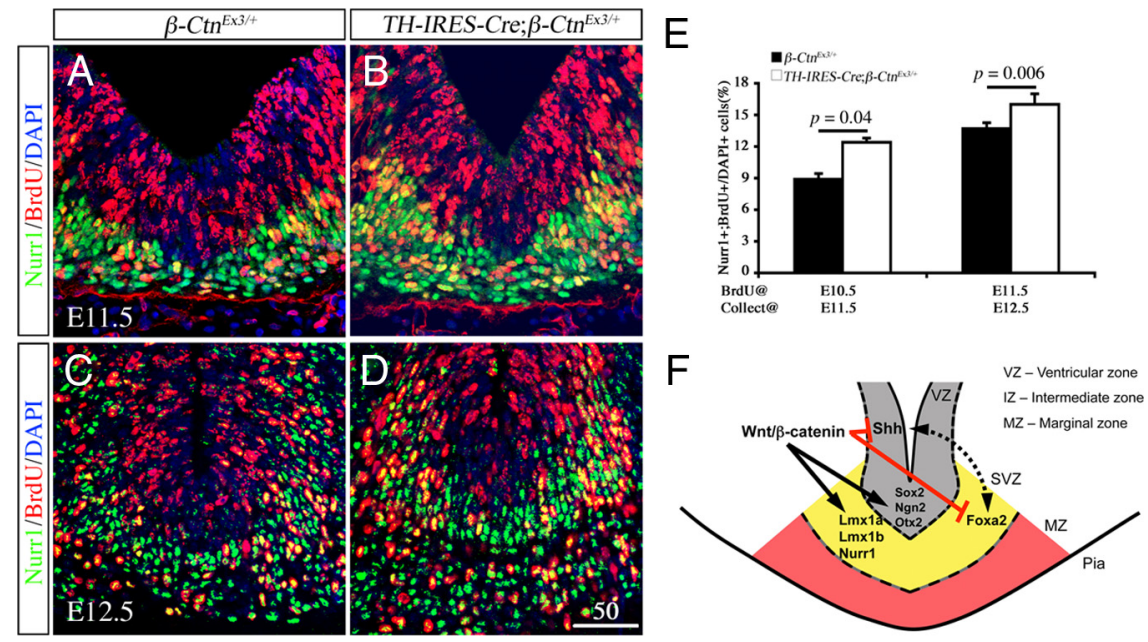

Figure 8. Increases in newly born postmitotic DA precursors in Th-IRES-Cre; $\beta$-Ctn ${ }^{E x /+}$ mutants. $A-D$, Neuronal birthdating experiments reveal increase newly generated postmitotic $\mathrm{DA}$ cells ( $\mathrm{BrdU}{ }^{+} ; \mathrm{Nurr}^{+}{ }^{+}$) from E10.5 to E11.5 and from E11.5 to E12.5. Scale bar: $\boldsymbol{A}-\boldsymbol{D}, 50 \mu \mathrm{m} . \boldsymbol{E}$, Quantification confirms the increased number of BrdU ${ }^{+} ; \mathrm{Nurr}^{+}{ }^{+}$cells atE11.5 and E12.5.F, A proposed model to indicate that Wnt $/ \beta$-catenin and Shh control the expression of distinct sets of transcription factors in the progenitors in vMB. Constitutive activation of Wnt $/ \beta$-catenin suppresses the expression of Shh and its downstream targets, including cyclin D1 and Foxa2.

Our current study provides additional in vivo evidence that activation of $\mathrm{Wnt} / \beta$-catenin signaling leads to a marked expansion of early DA progenitors that express Sox2, Ngn2, and Otx2, as well as an increase in the progenitors that express Lmxla, Lmx1b, and Nurr1 (Figs. 1, 8 F). Despite the expansion of these progenitors, however, activation of $\mathrm{Wnt} / \beta$-catenin perturbs cell cycle progression and reduces the production of $\mathrm{TH}^{+} \mathrm{DA}$ neurons in vMB (Figs. 2, 3). Interestingly, when cultured in the presence of Wnt5a, the progenitors from Shh-Cre; $\beta-C t n^{E x 3 /+}$ mutants differentiate into DA neurons in a manner similar to those from control (Fig. 3N). These results provide important insights into the recently published results in which forced expression of Lmxla in mESCs alone induces robust expression of Nurr1 and Pitx3, but only a limited number of these cells show properties of differentiated DA neurons (Chung et al., 2009). Furthermore, our results provide additional support that, when given the optimal growth conditions, such as excess Wnt5a, the progenitors expanded by the $\mathrm{Wnt} / \beta$-catenin signaling mechanisms have the potential to differentiate into mature DA neurons.

\section{Activation of $\mathrm{Wnt} / \boldsymbol{\beta}$-catenin antagonizes Shh and Foxa2 expression in the neurogenesis of DA neurons}

Several explanations can account for the failure for constitutive activation of $\mathrm{Wnt} / \beta$-catenin signaling to promote the differentiation of vMB progenitors into mature DA neurons in Shh-Cre; $\beta-C t n^{E \times 3 /+}$ mutants. First, as indicated above, analyses of the proliferation and cell cycle progression in the DA progenitors in Shh-Cre; $\beta-C t n^{E x 3 /+}$ mutants show much more progenitors in the $\mathrm{S}$ or $\mathrm{M}$ phase of the cell cycle. However, these mutant progenitors show reduced cell cycle exit (Fig. 2). Although the underlying cause(s) for the dysregulation of cell cycle progression in the DA progenitors of Shh-Cre; $\beta-C t n^{E x 3 /+}$ mutants is not entirely clear, it is possible that the reduced expression of cyclin D1 and perhaps other cell cycle genes in the vMB of these mutants may have contributed to this phenotype. Second, the expanded progenitors may be exposed to a different environment that may prevent or delay their differentiation into committed progenitors or postmitotic neurons. Consistent with this notion, progenitors from Shh-Cre; $\beta-C t n^{E x 3 /+}$ mutants can differentiate into DA neurons in the presence of Wnt5a just like those progenitors from control embryos (Fig. $3 N$ ).

The third explanation for the reduced production of DA neurons in Shh-Cre; $\beta-C t n^{E \times 3 /+}$ mutants is the significant downregulation of Shh and forkhead transcription factor Foxa2 expression in the vMB (Fig. 4). The downregulation of Shh begins as early as E10.5, and, by E12.5, no detectable Shh is present in vMB in these mutants. In contrast, no detectable downregulation of Foxa2 is present until E12.5. The downregulation of Foxa2 may be attributable to the loss of Shh. Alternatively, activation of $\mathrm{Wnt} / \beta$-catenin may directly or indirectly suppress the expression of Foxa2. Consistent with these results, expanded progenitors from Shh$C r e ; \beta-C t n^{E x 3 /+}$ mutants show limited potential to differentiate into DA neurons even when cultured in the presence of excess Shh, probably because of the severe reduction in Foxa2 expression (Figs. 3N, $4 L$ ). Similar antagonistic effects of $\mathrm{Wnt} / \beta$-catenin activation on the expression of Shh in the developing hindbrain have been reported in a recent study (Joksimovic et al., 2009). Remarkably, the antagonistic effects between Wnt/ $\beta$-catenin and Shh can be demonstrated in the differentiation of DA neurons using in vitro cultures of vMB progenitors and mESCs (Figs. 5, 6). These results support the model that Wnt/ $\beta$-catenin and Shh each control distinct downstream target genes that work cooperatively to control the development of DA neurons (Fig. 8F) (Chung et al., 2009). Constitutive activation of one signaling mechanism may perturb a delicate balance between $\mathrm{Wnt} / \beta$-catenin and Shh signaling mechanisms in the process of DA neurogenesis (Fig. 8 F). Curiously, previous studies have shown that loss of Shh in the vMB of Nestin-Cre;Sh ${ }^{\text {flox/flox }}$ or En $1^{\text {KICre/+}}$;Shh flox/flox mutants has no detectable effects on the expression of Lmxla, Lmx1b, Foxa1, or Foxa2 (Ferri et al., 2007; Lin et al., 2009). These studies raise the possibility that loss of Shh alone may not be sufficient to cause the phenotypes in the progenitors of Shh-Cre; $\beta-C t n^{E x 3 /+}$ mutants. It is possible that loss of Shh and Foxa2 in the Shh-Cre; $\beta-C t n^{E x 3 /+}$ mutants cooperatively block the differentiation of DA neurons. Alternatively, activation of Wnt/ $\beta$-catenin in the vMB of Shh$C r e ; \beta-C t n^{E x 3 /+}$ mutants may suppress additional target genes that influence the generation of DA neurons.

The phenotype that $S h h-C r e ; \beta-C t n^{E x 3 /+}$ mutants show a significant reduction in Foxa2 expression in $\mathrm{vMB}$ is reminiscent of those in Nestin-Cre; Foxa $2^{\text {flox/flox }}$ mutants, which show an expansion of Nurr ${ }^{+} ; \mathrm{TH}^{-}$cells and a significant reduction in Nurr1 ${ }^{+}$; $\mathrm{TH}^{+}$DA neurons from E12.5 to E18.5 (Ferri et al., 2007). Although Foxal null mutants also show a similar phenotype at E12.5, this deficit appears to be transient at E12.5 and is not detected at later developmental stages. It is unclear whether the effect of $\beta$-catenin activation to suppress the expression of Foxa 2 is mediated through direct binding of lymphoid enhancer factor/ $\mathrm{T}$-cell factor to the enhancer sequence of Foxa2. Alternatively, it is possible that downstream targets activated by $\beta$-catenin may negatively regulate the expression of Foxa2. Regardless of the mechanism, it is most likely that downregulation of Foxa2 may in 
part contribute to the reduced generation of DA neurons in these mutants.

\section{Implications of Wnt/ $\beta$-catenin and Shh in the generation of DA neurons from stem cells}

The marked expansion of DA progenitors in the vMB of Shh-Cre; $\beta-C t n^{E x 3 /+}$ mutants raises the possibility that $\mathrm{Wnt} / \beta$-catenin signaling may be a feasible target to promote the generation of DA neurons from neural stem cells. In support of this, both Wnt1 and the GSK3 $\beta$ inhibitor CT99021 promote the production of DA neurons in vMB progenitor cell and mESC cultures (Figs. 5, 6). Despite these encouraging results, simultaneous treatment with optimal doses of Wnt1 or CT99021 and Shh in vMB progenitors or mESCs shows no additive or synergistic effects, whereas treatments with higher doses of CT99021 and Shh actually suppress the generation of DA neurons (Figs. 5, 6). Furthermore, sequential treatments of Shh and CT99021 also do not show additional benefits (Fig. 5). These results suggest that a more detailed knowledge of the interaction between $\mathrm{Wnt} / \beta$-catenin and Shh signaling in different vMB cells may further aid in the development of improved protocols for the generation of DA neurons in embryonic stem cell cultures. As a proof of principle, we report that cell-type-specific activation of $\mathrm{Wnt} / \beta$-catenin in midline DA progenitors, using Th-IRES-Cre, leads to increases in Nurr ${ }^{+}$ precursors as well as in mature DA neurons both in prenatal and postnatal brains (Figs. 7, 8). Together, these encouraging results support the notion that, although a broad activation of $\mathrm{Wnt} / \beta$ catenin remains an effective means to promoting the expansion of DA progenitors, a restricted activation in midline progenitors provides beneficial effects in promoting the generation of DA neurons. We suggest that Wnt/ $\beta$-catenin activation in specific cell types may become a valuable strategy to improve the DA differentiation of embryonic stem cells.

\section{References}

Andersson ER, Prakash N, Cajanek L, Minina E, Bryja V, Bryjova L, Yamaguchi TP, Hall AC, Wurst W, Arenas E (2008) Wnt5a regulates ventral midbrain morphogenesis and the development of A9-A10 dopaminergic cells in vivo. PLoS ONE 3:e3517.

Ang SL (2006) Transcriptional control of midbrain dopaminergic neuron development. Development 133:3499-3506.

Arenas E (2008) Foxa2: the rise and fall of dopamine neurons. Cell Stem Cell 2:110-112.

Barberi T, Klivenyi P, Calingasan NY, Lee H, Kawamata H, Loonam K, Perrier AL, Bruses J, Rubio ME, Topf N, Tabar V, Harrison NL, Beal MF, Moore MA, Studer L (2003) Neural subtype specification of fertilization and nuclear transfer embryonic stem cells and application in parkinsonian mice. Nat Biotechnol 21:1200-1207.

Bjorklund A, Lindvall O (1984) Dopamine-containing systems in the CNS. In: Handbook of chemical neuroanatomy. Amsterdam: Elsevier.

Castelo-Branco G, Arenas E (2006) Function of Wnts in dopaminergic neuron development. Neurodegener Dis 3:5-11.

Castelo-Branco G, Wagner J, Rodriguez FJ, Kele J, Sousa K, Rawal N, Pasolli HA, Fuchs E, Kitajewski J, Arenas E (2003) Differential regulation of midbrain dopaminergic neuron development by Wnt-1, Wnt-3a, and Wnt-5a. Proc Natl Acad Sci U S A 100:12747-12752.

Castelo-Branco G, Andersson ER, Minina E, Sousa KM, Ribeiro D, Kokubu C, Imai K, Prakash N, Wurst W, Arenas E (2010) Delayed dopaminergic neuron differentiation in Lrp6 mutant mice. Dev Dyn 239:211-221.

Chung S, Leung A, Han BS, Chang MY, Moon JI, Kim CH, Hong S, Pruszak J, Isacson O, Kim KS (2009) Wnt1-lmxla forms a novel autoregulatory loop and controls midbrain dopaminergic differentiation synergistically with the SHH-FoxA2 pathway. Cell Stem Cell 5:646-658.

Danielian PS, McMahon AP (1996) Engrailed-1 as a target of the Wnt-1 signalling pathway in vertebrate midbrain development. Nature 383:332-334.

Ferri AL, Lin W, Mavromatakis YE, Wang JC, Sasaki H, Whitsett JA, Ang SL
(2007) Foxa1 and Foxa2 regulate multiple phases of midbrain dopaminergic neuron development in a dosage-dependent manner. Development 134:2761-2769.

Gulacsi AA, Anderson SA (2008) Beta-catenin-mediated Wnt signaling regulates neurogenesis in the ventral telencephalon. Nat Neurosci 11:1383-1391.

Harada N, Tamai Y, Ishikawa T, Sauer B, Takaku K, Oshima M, Taketo MM (1999) Intestinal polyposis in mice with a dominant stable mutation of the beta-catenin gene. EMBO J 18:5931-5942.

Harfe BD, Scherz PJ, Nissim S, Tian H, McMahon AP, Tabin CJ (2004) Evidence for an expansion-based temporal Shh gradient in specifying vertebrate digit identities. Cell 118:517-528.

Hedlund E, Pruszak J, Lardaro T, Ludwig W, Viñuela A, Kim KS, Isacson O (2008) Embryonic stem cell-derived Pitx3-enhanced green fluorescent protein midbrain dopamine neurons survive enrichment by fluorescenceactivated cell sorting and function in an animal model of Parkinson's disease. Stem Cells 26:1526-1536.

Hynes M, Porter JA, Chiang C, Chang D, Tessier-Lavigne M, Beachy PA, Rosenthal A (1995) Induction of midbrain dopaminergic neurons by Sonic hedgehog. Neuron 15:35-44.

Jeong Y, Epstein DJ (2003) Distinct regulators of Shh transcription in the floor plate and notochord indicate separate origins for these tissues in the mouse node. Development 130:3891-3902.

Joksimovic M, Yun BA, Kittappa R, Anderegg AM, Chang WW, Taketo MM, McKay RD, Awatramani RB (2009) Wnt antagonism of Shh facilitates midbrain floor plate neurogenesis. Nat Neurosci 12:125-131.

Lin W, Metzakopian E, Mavromatakis YE, Gao N, Balaskas N, Sasaki H, Briscoe J, Whitsett JA, Goulding M, Kaestner KH, Ang SL (2009) Foxal and Foxa2 function both upstream of and cooperatively with Lmxla and Lmxlb in a feedforward loop promoting mesodiencephalic dopaminergic neuron development. Dev Biol 333:386-396.

Lindeberg J, Usoskin D, Bengtsson H, Gustafsson A, Kylberg A, Söderström S, Ebendal T (2004) Transgenic expression of Cre recombinase from the tyrosine hydroxylase locus. Genesis 40:67-73.

McMahon AP, Bradley A (1990) The Wnt-1 (int-1) proto-oncogene is required for development of a large region of the mouse brain. Cell 62:1073-1085.

Megason SG, McMahon AP (2002) A mitogen gradient of dorsal midline Wnts organizes growth in the CNS. Development 129:2087-2098.

Omodei D, Acampora D, Mancuso P, Prakash N, Di Giovannantonio LG, Wurst W, Simeone A (2008) Anterior-posterior graded response to Otx2 controls proliferation and differentiation of dopaminergic progenitors in the ventral mesencephalon. Development 135:3459-3470.

Parish CL, Parisi S, Persico MG, Arenas E, Minchiotti G (2005) Cripto as a target for improving embryonic stem cell-based therapy in Parkinson's disease. Stem Cells 23:471-476.

Parish CL, Castelo-Branco G, Rawal N, Tonnesen J, Sorensen AT, Salto C, Kokaia M, Lindvall O, Arenas E (2008) Wnt5a-treated midbrain neural stem cells improve dopamine cell replacement therapy in parkinsonian mice. J Clin Invest 118:149-160.

Prakash N, Wurst W (2006) Genetic networks controlling the development of midbrain dopaminergic neurons. J Physiol 575:403-410.

Prakash N, Brodski C, Naserke T, Puelles E, Gogoi R, Hall A, Panhuysen M, Echevarria D, Sussel L, Weisenhorn DM, Martinez S, Arenas E, Simeone A, Wurst W (2006) A Wnt1-regulated genetic network controls the identity and fate of midbrain-dopaminergic progenitors in vivo. Development 133:89-98.

Puelles E, Annino A, Tuorto F, Usiello A, Acampora D, Czerny T, Brodski C, Ang SL, Wurst W, Simeone A (2004) Otx2 regulates the extent, identity and fate of neuronal progenitor domains in the ventral midbrain. Development 131:2037-2048.

Rodríguez-Gómez JA, Lu JQ, Velasco I, Rivera S, Zoghbi SS, Liow JS, Musachio JL, Chin FT, Toyama H, Seidel J, Green MV, Thanos PK, Ichise M, Pike VW, Innis RB, McKay RD (2007) Persistent dopamine functions of neurons derived from embryonic stem cells in a rodent model of Parkinson disease. Stem Cells 25:918-928.

Sasaki H, Hui C, Nakafuku M, Kondoh H (1997) A binding site for Gli proteins is essential for HNF-3beta floor plate enhancer activity in transgenics and can respond to Shh in vitro. Development 124:1313-1322.

Schulte G, Bryja V, Rawal N, Castelo-Branco G, Sousa KM, Arenas E (2005) Purified Wnt-5a increases differentiation of midbrain dopaminergic cells and dishevelled phosphorylation. J Neurochem 92:1550-1553.

Smidt MP, Burbach JP (2007) How to make a mesodiencephalic dopaminergic neuron. Nat Rev Neurosci 8:21-32. 
Sousa KM, Villaescusa JC, Cajanek L, Ondr JK, Castelo-Branco G, Hofstra W, Bryja V, Palmberg C, Bergman T, Wainwright B, Lang RA, Arenas E (2010) WNT2 regulates progenitor proliferation in the developing ventral midbrain. J Biol Chem 285:7246-7253.

Stuebner S, Faus-Kessler T, Fischer T, Wurst W, Prakash N (2010) Fzd3 and Fzd6 deficiency results in a severe midbrain morphogenesis defect. Dev Dyn 239:246-260.

Takeshima T, Shimoda K, Johnston JM, Commissiong JW (1996) Standardized methods to bioassay neurotrophic factors for dopaminergic neurons. J Neurosci Methods 67:27-41.

Tang M, Miyamoto Y, Huang EJ (2009) Multiple roles of beta-catenin in controlling the neurogenic niche for midbrain dopamine neurons. Development 136:2027-2038.

Thomas KR, Capecchi MR (1990) Targeted disruption of the murine int-1 proto-oncogene resulting in severe abnormalities in midbrain and cerebellar development. Nature 346:847-850.

Vernay B, Koch M, Vaccarino F, Briscoe J, Simeone A, Kageyama R, Ang SL (2005) Otx2 regulates subtype specification and neurogenesis in the midbrain. J Neurosci 25:4856-4867.

Ye W, Shimamura K, Rubenstein JL, Hynes MA, Rosenthal A (1998) FGF and Shh signals control dopaminergic and serotonergic cell fate in the anterior neural plate. Cell 93:755-766.

Zhang J, Huang EJ (2006) Dynamic expression of neurotrophic factor receptors in postnatal spinal motoneurons and in mouse model of ALS. J Neurobiol 66:882-895.

Zhang J, Pho V, Bonasera SJ, Holtzman J, Tang AT, Hellmuth J, Tang S, Janak PH, Tecott LH, Huang EJ (2007) Essential function of HIPK2 in TGFbetadependent survival of midbrain dopamine neurons. Nat Neurosci 10:77-86. 